Book Review

\title{
Applications of Fluorescence in Situ Hybridization in Radiation Cytogenetic Biodosimetry and Population Monitoring
}

\author{
Adayabalam S. Balajee *
}

Cytogenetics Biodosimetry Laboratory, Radiation Emergency Assistance Center and Training Site, Oak Ridge Institute for Science and Education, Oak Ridge Associated Universities, Oak Ridge, TN 37830, USA; E-Mail: adayabalam.balajee@orau.org

* Correspondence: Adayabalam S. Balajee; E-Mail: adayabalam.balajee@orau.org

Academic Editor: Thomas Liehr

Special Issue: Applications of Fluorescence in Situ Hybridization

OBM Genetics

2018 , volume 2 , issue 4

doi:10.21926/obm.genet.1804042
Received: August 26, 2018

Accepted: September 29, 2018

Published: October 19, 2018

\begin{abstract}
:
The technique of in situ hybridization (ISH) using radioactively labeled DNA probes was first described in the late 1960s and early 1970s. The first use of fluorescence in situ hybridization (FISH) was reported in 1980s where RNA labeled with a fluorophore at the $3^{\prime}$ end was used to detect specific DNA sequences. Since then, the technique has undergone various modifications for detecting single genes, chromosomes and whole genomes on various targets such as interphase nucleus, prematurely condensed chromosomes, metaphase chromosomes, fresh and paraffinized tissue sections. Although FISH is quite frequently used in clinical diagnostics, its use has recently been extended to the field of radiation biodosimetry where both stable (translocations) and unstable aberrations (dicentrics and rings) are detected with high resolution for estimating the absorbed radiation dose in humans after incidental, accidental or occupational exposure to ionizing radiation. This review summarizes the diverse applications of FISH in radiation biodosimetry that range from radiation dose estimation to prediction of deterministic (i.e. acute radiation syndrome severity) and stochastic (i.e. genetic mutations and cancer) effects in the affected human population.
\end{abstract}

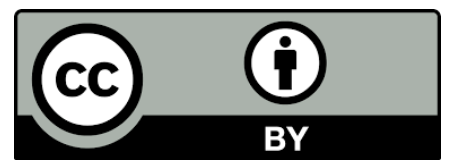

(C) 2018 by the author. This is an open access article distributed under the conditions of the Creative Commons by Attribution License, which permits unrestricted use, distribution, and reproduction in any medium or format, provided the original work is correctly cited. 


\section{Keywords}

Fluorescence in situ hybridization; metaphase chromosomes; dicentric chromosome assay; translocations; inversions; retrospective biodosimetry; radiation dose assessment; radiological/nuclear mass-casualty incidents and carcinogenesis

\section{Introduction}

Several endogenous and exogenous DNA damaging agents constantly threaten the integrity of genomic DNA in prokaryotes and eukaryotes. Endogenous agents include the generation of reactive oxygen species (ROS) and reactive nitrogen species (RNS) through normal cellular metabolic activities. Exogenous DNA damaging agents such as ultraviolet (UV) light and ionizing radiation (IR) induce different types of lesions ranging from bulky DNA helix distorting adducts to DNA single strand breaks, double strand breaks, base damage and DNA-protein crosslinks. Occurrence of two or more of these lesions within a single helical turn of DNA in close proximity can lead to the formation of clustered lesions. These simple and complex lesions, if mis-repaired, will be manifested as unstable and stable chromosomal aberrations. While chromosomal aberrations in somatic cells can lead to cancer development processes, germ cells with chromosome anomalies can result in heritable genetic disorders. Prior to the development of Fluorescence in situ hybridization (FISH) technique, congenital and DNA damage induced chromosomal aberrations were analyzed by conventional chromosome banding techniques.

Development of in situ hybridization (ISH) technique using radioactively labeled DNA/RNA probes in the late 1960s and early 1970s [1-4] has completely revolutionized the study of chromosomes owing to its sensitivity, stability and reliability over the conventional chromosome staining techniques. Subsequent advancements made in DNA and RNA labeling methods for genes, chromosomes and whole genomes have facilitated the analysis of both numerical and structural chromosomal aberrations in both basic and clinical laboratories. The nature and frequency of ionizing radiation (IR) induced chromosomal aberrations largely depend on quality, which is defined by Linear Energy Transfer (LET). LET refers to the amount of energy deposited by an ionizing particle on a material per unit distance of traverse. Low LET radiation includes X-rays and $\gamma$-rays that produce sparsely ionizing events. In contrast, high LET radiation such as $\alpha$-particles (emitted from Plutonium 239 and Americium 241) and neutrons generates densely ionizing events.

Initially, IR induced chromosomal aberrations in human peripheral lymphocytes were primarily detected by Giemsa staining. Bender and Gooch [5] first described the use of a unique chromosome anomaly known as "dicentric chromosome" for estimating the absorbed radiation dose in humans. Illegitimate rejoining of DNA double strand breaks (DSBs) induced in two or more chromosomes results in the formation of a dicentric chromosome. A schematic diagram describing the mechanism for IR induced dicentric chromosome formation is shown in Figure 1. Formation of dicentric chromosomes (abnormal chromosomes with two centromeres) is highly specific to IR and occurs in a radiation dose dependent manner in human lymphocytes under both in vivo and ex vivo conditions. Although Giemsa staining of chromosomes is still the preferred and cost effective method for detecting dicentric chromosomes, FISH based methodology using either pan centromeric DNA probe or centromere specific peptide nuclei acid (PNA) probe has been gaining 
prominence because of ease of detection and high resolution. Additionally, development of different fluorescently labeled probes for specific genes and chromosomes have enabled the detection of IR induced chromosomal aberrations in the cytogenetic follow up studies performed on the victims of mass-casualty incidents at Chernobyl [6, 7] and Goiania [8, 9]. Generation of DNA probes for multicolor FISH (mFISH) and spectral karyotyping (SKY) in the late 1990s for painting the entire human genome has allowed the monitoring of genome wide chromosomal alterations in general and IR induced complex chromosomal exchanges in particular. Subsequent development of chromosome specific multicolor band probe [10] has improved the detection of intrachromosomal exchange events (paracentric and pericentric inversions) that are efficiently induced by high doses of IR [11-15]. Availability of gene specific probes has facilitated the detection of copy number changes and gene loci interactions not only in the metaphase chromosomes but also in the interphase nucleus.

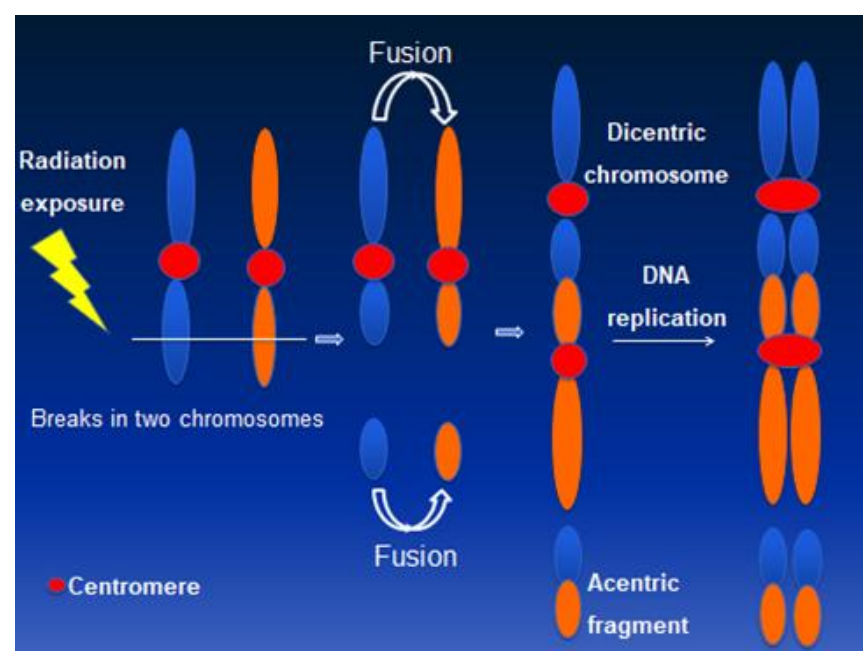

Figure 1 A schematic diagram showing ionizing radiation induced dicentric chromosome formation due to mis-rejoining of DNA double strand breaks induced on two chromosomes. Dicentric chromosomes are invariably accompanied by acentric fragments.

Availability of FISH probes for specific chromosomes and the entire human genome allows the detection of a whole spectrum of interchromosomal (dicentrics translocations and fragments) and intrachromosomal (rings, deletions and inversions) aberrations induced by various DNA damaging agents including IR. Representative FISH pictures for IR induced asymmetrical (dicentrics and rings) and symmetrical (translocations and inversions) chromosome aberrations are shown in Figure 2. In recent years, attempts have been made to compare the ratios of different chromosome aberration types for defining the "cytogenetic fingerprints" specific for different DNA damaging agents. There are four ratios that are commonly used: (I) "F"- ratio of interchromosomal exchanges to intrachromosomal inter-arm exchanges (i.e. dicentrics to centric rings), (II) " $G$ " - ratio of intrachromosomal intra-arm exchanges to intrachromosomal inter-arm exchanges (i.e. interstitial deletions to centric rings; paracentric to pericentric inversions), (III) " $\mathrm{C}$ "-ratio of complex exchanges to simple exchanges (i.e. translocations and insertions) and (IV) " $\mathrm{H}$ "-ratio of intra-arm intrachromosomal changes to interchromosomal exchanges (i.e. interstitial deletions to dicentrics). Frequency of occurrence of different types of chromosomal aberrations induced as a 
function of radiation quality is summarized in Table 1 . Comparisons of different ratios for interand intrachromosomal aberrations would not have been possible without the development of FISH based technologies. This review summarizes the current and future applications of various FISH based techniques in detecting the absorbed radiation dose in occupationally or accidentally exposed human population.

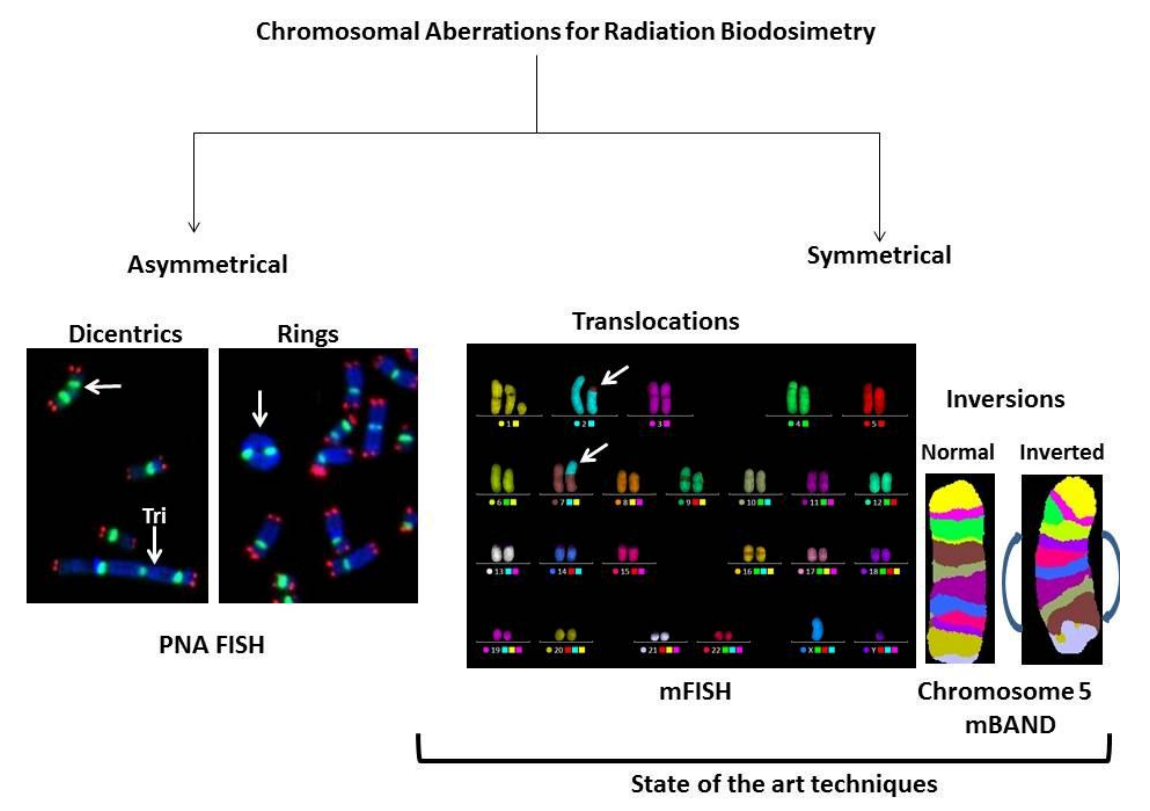

Figure 2 Use of FISH based technologies for detecting asymmetrical (dicentrics and rings) and symmetrical (translocations and inversions) chromosomal aberrations in ex vivo irradiated human lymphocytes.

Table 1 Comparison of various ratios of inter- and intrachromosomal aberrations induced by different radiation qualities

\begin{tabular}{|c|c|c|c|c|}
\hline Ratio & Type of Aberrations & Radiation Quality & Range & Ref \\
\hline \multirow{3}{*}{$\mathrm{F}$} & Interchromosomal & $\gamma$-rays (2 Gy) & $10-15$ & 95 \\
\hline & exchanges to & $\gamma$-rays (5 Gy) & $9-11$ & 95 \\
\hline & $\begin{array}{l}\text { intrachromosomal inter- } \\
\text { arm changes }\end{array}$ & $\begin{array}{l}{ }^{56} \mathrm{Fe} \text { ions (1 GeV/nucleon, } 140 \mathrm{keV} / \mu \mathrm{m} \text {; } \\
3 \mathrm{~Gy})\end{array}$ & $9-11$ & 95 \\
\hline G & $\begin{array}{l}\text { Intrachromosomal intra- } \\
\text { arm exchanges to } \\
\text { intrachromosomal inter- } \\
\text { arm exchanges }\end{array}$ & $\gamma$-rays $(2,4$ and $6 \mathrm{~Gy})$ & $2-4$ & 94 \\
\hline \multirow[b]{2}{*}{$\mathrm{H}$} & Intra-arm & $\gamma$-rays $(2,4$ and $6 \mathrm{~Gy})$ & $0.2-0.4$ & 94 \\
\hline & $\begin{array}{l}\text { intrachromosomal } \\
\text { changes to } \\
\text { interchromosomal } \\
\text { exchanges }\end{array}$ & $\alpha$-particles ( ${ }^{241} \mathrm{Am}$ source; 0.1-1 Gy) & $0.4-0.5$ & 93 \\
\hline \multirow{4}{*}{ C } & Complex exchanges to & Protons (1 Gy; $28.5 \mathrm{keV} / \mu \mathrm{m})$ & $0.1-0.2$ & 96 \\
\hline & simple exchanges & Helium 4-ion (1 Gy; 62 keV/ $\mu \mathrm{m})$ & $0.1-0.2$ & 96 \\
\hline & & Carbon ion (1 Gy; $96 \mathrm{keV} / \mu \mathrm{m})$ & $0.2-0.3$ & 96 \\
\hline & & 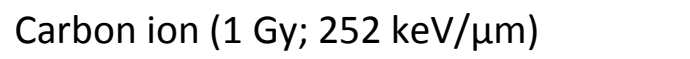 & $0.6-0.7$ & 96 \\
\hline
\end{tabular}




\section{FISH Based Detection of Dicentric Chromosomes for Absorbed Radiation Dose Assessment in Humans after Occupational and Accidental Exposure}

Human exposure to IR has become almost inevitable due to its increased use in various industrial, research and medical diagnostic applications. In the case of human exposure to radiation, it is imperative to determine the absorbed radiation dose, which will assist the physicians in making appropriate medical treatment/countermeasures. Bender and Gooch in 1962 [5] suggested that the formation of a unique chromosome anomaly known as "dicentric chromosome" in the peripheral blood lymphocytes can be reflective of absorbed radiation dose in humans. Since then, "Dicentric Chromosome Assay (DCA)" has been the preferred method for radiation dose assessment of occupationally or accidentally exposed humans. DCA was utilized for radiation dose assessment in the victims of several well-known radiation accidents such as Chernobyl [6, 16, 17], Goiania [18-20] and Fukushima-Daiichi [21-23], to name a few. DCA is considered to be the gold standard for absorbed dose assessment owing to its high specificity and sensitivity to IR. A few unique features make the DCA as the universally accepted biodosimeter: (I) low base line frequency of dicentric chromosomes (1-2 dicentrics/1000 metaphase cells) which is largely independent of age and sex; (II) assay is minimally invasive in nature and III) dicentric chromosome formation is highly specific to IR with sensitivity of detection ranging from 0.05-7.5 Gy of low LET radiations (X-rays and $\gamma$-rays) in most cases. Estimation of radiation doses less than $0.05 \mathrm{~Gy}$ requires the analysis of several thousands of cells since the level of DNA damage is expected to be extremely low with a non-homogenous distribution of cells with dicentric chromosomes. Every cytogenetic biodosimetry laboratory must develop a suitable calibration curve that includes the dicentric chromosome measurements for low dose ranges (0.05-0.1 Gy) for reliable dose estimation following chronic low dose exposures. Frequency of dicentric chromosomes obtained from suspected or radiation exposed human blood sample is fitted to a calibration curve for estimating the whole body absorbed radiation dose (Gy) using CABAS (Chromosome ABerration cAlculation Software; [24]) with lower and upper dose limits at $95 \% \mathrm{Cl}$ (Confidence Interval). Calibration curve or radiation dose response curve is constructed using the dicentric chromosomes frequencies obtained after ex vivo irradiation of lymphocytes with known radiation doses. CABAS utilizes the maximum likelihoods for fitting the calibration data to a linear quadratic fashion for low LET radiation. A minimum of 4 dicentric chromosomes in 1000 cells would be required to get a radiation dose estimate that is statistically greater than zero. The yield of low LET radiation induced exchange type chromosomal aberrations including dicentrics can be estimated by the equation $y=c+\alpha D+\beta D^{2}$ where $y$ is the yield of aberrations per metaphase cell, $c$ is the baseline frequency, $\alpha$ and $\beta$ are the coefficients of exchange type aberrations induced by a single and double electron tracks respectively and $D$ is the absorbed dose. Since there is an increased probability of inducing two breaks by a single ionizing track with high LET radiation, $\alpha D$ becomes more prominent and so the yield of exchange type aberrations can be estimated by $y=c+\alpha D$. As the $\alpha$ coefficient (exchange type aberrations induced by a single ionizing track) is predominant for high LET radiation, dose response curve tends to be linear for the yield of chromosomal aberrations while the curve for low LET radiation tends to be linear quadratic because of $\alpha$ and $\beta$ coefficients.

Although DCA is a reliable biodosimeter for estimating the absorbed radiation dose, certain criticality accident scenarios involving non-uniform exposure and mixed beam exposure (i.e. 
neutrons and $\gamma$-rays) may obscure the accuracy of dose estimation. Experience gained from the past radiological accidents at Chernobyl, Goiania, Tokaimura and Fukushima-Daiichi indicates that radiation exposure in most cases occurs in a non-uniform manner. In the case of partial body exposure scenarios, mixing of irradiated lymphocytes with non-irradiated lymphocytes may dilute the yield of dicentrics, thereby resulting in an underestimation of radiation dose. Therefore, irradiated fraction of lymphocytes or volume of the body exposed becomes a critical confounding factor for accurate dose estimation. It should be remembered that the overall dicentric frequency estimated per metaphase cell remains the same irrespective of either partial or whole body exposure but the distribution pattern of dicentrics observed in the aberrant cells may be different between these two exposure scenarios. Two mathematical models have been developed to account for the distribution of aberration yield: (1) Dolphin's contaminated Poisson distribution [25] and (2) Sasaki's QDR (quantity of dicentrics and rings) method [26]. In Dolphin's method, the volume of unexposed body is calculated by analyzing the over dispersed distribution of dicentric chromosomes in all the cells relative to the expected Poisson distribution of the irradiated cells. QDR method considers only the fraction of damaged cells with dicentrics and rings for dose estimation. In vitro simulation experiments-where different fractions of irradiated blood samples ( $25 \%, 50 \%$ and $75 \%$ and so on) are mixed with non-irradiated blood samples- demonstrated that the DCA assay can distinguish non-uniform exposure from whole body exposure reasonably well only when the irradiated blood fraction exceeds $30 \%$ and that the radiation dose is high enough to cause over dispersion of dicentric chromosome distribution. Partial body exposure exhibits over dispersion of dicentrics as opposed to under dispersion for whole body exposure. Mixed beam exposure can also complicate the interpretation of the dose estimated by DCA if information is lacking on physical determination of dose ratio between the two radiation qualities. In the absence of ratio estimate, a Bayesian approach can be used as described by Brame and Groer [27]. Another limiting factor is the decline of dicentric chromosomes over time and therefore DCA needs to be performed within a reasonable amount of time ( 4 weeks) after exposure. Lloyd et al. [28] suggested a half-life of 3 years for the decline of dicentric chromosomes (cells with unstable chromosomal aberrations are eliminated and replaced by newly produced lymphocytes without any dicentrics). Therefore, a correction factor is required for the dose estimation of samples delayed for more than a few months which otherwise will be underestimated. However, decline of dicentric chromosome yield cannot be always expressed as a function of time as other confounding factors such as infections and inter-individual variation owing to genetic makeup need to be considered.

It is a general practice for most of the cytogenetic laboratories worldwide to use a buffered Giemsa solution for dicentric chromosome detection. While this technique is cost effective, a substantial cytogenetic experience is required for accurately scoring the dicentric chromosome frequency. Technical difficulties may arise even for the experienced cytogeneticists when the quality of chromosome spreads is sub-optimal with a number of overlapping chromosomes or chromosome arms. An alternative and effective methodology is the FISH technique where a pan centromeric DNA probe or human centromere specific peptide nucleic acid (PNA) probe is used to detect the abnormal chromosomes with two, three and four centromeric regions. A distinct advantage of FISH is that chromosome overlapping is not a constraining factor since the centromeric regions are preferentially labeled for detection. Representative pictures for Giemsa and FISH based detection of dicentric chromosomes in human peripheral blood lymphocytes are 
shown in Figure $3 \mathrm{~A}$ and B. A typical dose-response calibration curve obtained for ${ }^{137}$ Cs $\gamma$-rays for various radiation doses in human peripheral blood lymphocytes is shown in Figure $3 C$.
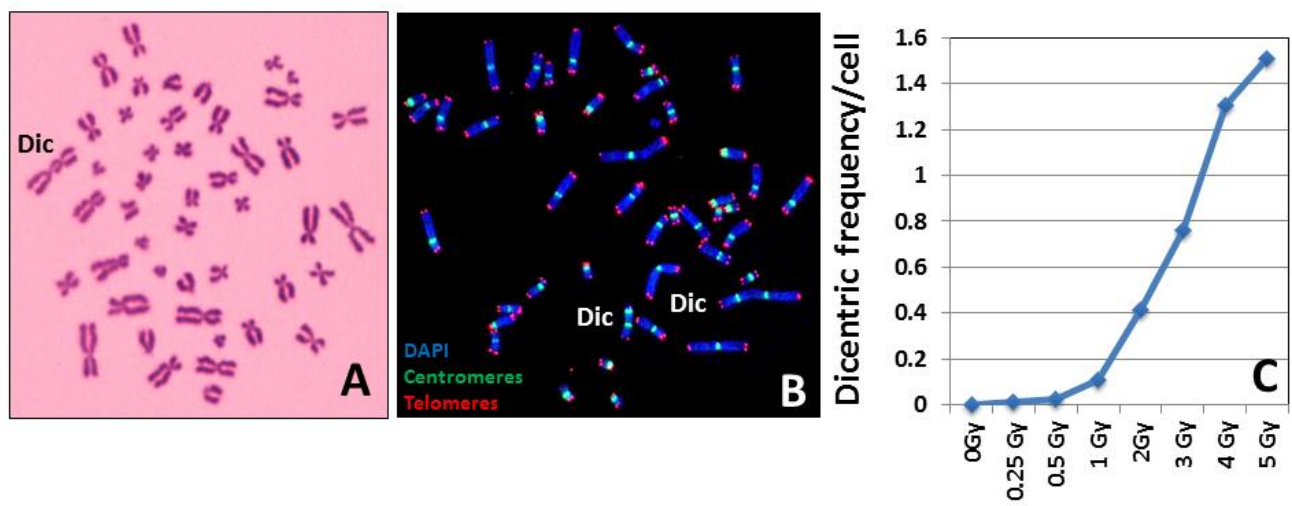

Radiation Dose

Figure 3 Giemsa (A) and FISH (B) based detection of dicentric chromosomes. Resolution and sensitivity of detection by the FISH technique are superior to the conventional Giemsa staining technique. (C) A typical radiation dose response curve generated from the dicentric chromosome frequencies obtained after ex vivo irradiation of human lymphocytes with known doses of $\gamma$-rays.

Bolzan and Bianchi [29] utilized the telomeric PNA probe for detecting incomplete acentric fragments arising from the terminal and interstitial regions after bleomycin (a radiomimetic agent) treatment of Chinese hamster embryo (CHE) cells. The dicentric chromosome frequency dramatically increases at high radiation doses (>4 Gy) and FISH technique has been proven to be more sensitive than Giemsa analysis. Shi et al. [30] suggested that the radiation dose estimated by FISH was more accurate than the Giemsa staining method. M'kacher et al. [31] reported a significantly higher frequency of dicentrics detected by FISH when compared to uniform staining by Giemsa. In addition, improved resolution and sensitivity in dicentric chromosome detection by FISH has resulted in a better estimation of DSBs, especially at low radiation doses. Further, development of FISH based TCScore (telomeric centromeric score) algorithm detected 95\% of manually scored dicentrics compared to only $50 \%$ by Giemsa based DCScore illustrating the sensitivity and accuracy of FISH. Unequivocal detection of centromeric regions by FISH enhances the accuracy of dicentric chromosome analysis by avoiding the inclusion of false positives resulting from overlapping of chromosomes or chromosome arms, which would overestimate the dicentric frequency. Ring chromosome belongs to the category of unstable chromosome aberrations and FISH can detect the ring chromosomes with centromeres (centric rings). Although ring chromosomes are formed at low frequencies after IR exposure, most cytogenetic laboratories consider both dicentric chromosomes and rings for absorbed radiation dose estimation in humans [32-34].

In the case of radiological or nuclear mass casualty incidents, several hundreds and thousands of people may get exposed to radiation. lonizing radiation causes adverse health effects in humans including mortality from acute radiation syndrome with a LD50/60 value of $3.5 \mathrm{~Gy}-4.5 \mathrm{~Gy}$ without therapy and 6.5 Gy-7.5 Gy with appropriate therapy. Further, IR can cause stochastic effects resulting in increased mortality from cancer. Therefore rapid individualized dose estimation is 
critical for making the "lifesaving" decision. The conventional dicentric chromosome assay requires the stimulation of peripheral blood lymphocytes in vitro for at least 48 hrs with an additional time of 24-48 hrs for cell fixation, dicentric chromosome analysis and radiation dose estimation.

Timely evaluation of dicentric chromosomes for dose estimation in mass casualty radiological or nuclear incidents provides a bottleneck due to restricted number of cytogenetic biodosimetry laboratories and trained personnel. Several efforts have been made in the recent past to make the DCA suitable for mass casualty incidents: (I) optimization of chromosome preparation [35], (II) automated scoring [36-42], (III) sample tracking [43], (IV) establishment of cytogenetic networks [44-46] and (V) development of electronic tools for sharing digital images among the national and international cytogenetic biodosimetry laboratories to increase surge capacity for dicentric scoring [47-50]. Additionally, attempts have been made to minimize the inter-laboratory variation(s) in dicentric chromosome analysis by developing a Standard Operating Procedure (SOP), a common calibration curve and participation in annual inter-laboratory comparison exercise for competency [47, 48, 51]. Application of FISH based techniques has definitely helped in developing high throughput automated image analysis platforms for rapid radiation biodosimetry. As mentioned before, FISH based TCScore (telomeric centromeric score) algorithm detected $95 \%$ of manually scored dicentrics and was found superior to Giemsa based DCScore [52].

To circumvent the technical limitations of DCA, an alternative technique known as premature chromosome condensation (PCC) is routinely used for rapid radiation dose estimation. The PCC technique, which involves the fusion of human G0/G1 lymphocytes with Chinese hamster ovary ( $\mathrm{CHO}$ ) mitotic cells, is distinctly advantageous because this technique can be performed immediately after blood collection alleviating the need of lymphocyte culture in vitro for 48 hrs. FISH is the method of choice for detecting IR induced dicentric chromosomes in PCCS as the centromeric regions are not usually detectable by the conventional Giemsa staining. Using a combination of PCC and FISH method, Karachristou et al. [52] constructed a radiation dose response curve up to $20 \mathrm{~Gy}$. This approach has a great potential for a rapid categorization of exposed people in the case of mass-casualty incidents. It must be emphasized that the PCC technique is yet to be verified and validated for use on clinical samples.

The classical cell fusion using either inactivated Sendai virus or polyethylene glycol yields PCCs in G1 phase. Recently Calyculin A, a protein phosphatase inhibitor, is routinely used to generate G2 PCCs from human cells [53-56]. Calyculin A induced G2 PCC technique enables the scoring of dicentric chromosomes induced by high radiation doses (10-25 Gy) and it is highly advantageous for analyzing partial body exposures exceeding $10 \mathrm{~Gy}$. As with G1 PCCs, FISH is required for centromere detection in G2 PCCs. Several studies have demonstrated the suitability of using a combination of G2-PCC and FISH techniques for accurate dose estimation especially when radiation doses are in the range of $10-20 \mathrm{~Gy}$. Calyculin A induced G2-PCC technique is certainly advantageous as the number of metaphase cells for analysis is highly restricted at higher radiation doses (> $5 \mathrm{~Gy}$ ) due to reduced in vitro proliferation of lymphocytes. Further, G2-PCC is the preferred technique for chromosomal aberration analysis after high LET radiation exposure (i.e. $\alpha$ particles, fission neutrons, carbon ions, and heavy iron ions) that generates a 3-4 fold higher induction of DNA double strand breaks relative to X-rays and $\gamma$-rays.

In a few radiation accident victims, chemically induced PCC technique was effectively used in combination with FISH for radiation dose assessment. As the lymphocyte count was extremely low, 
the PCC technique was utilized to estimate the radiation dose in 3 severely exposed patients in a uranium reprocessing facility operated by the Japan Nuclear Fuel Conversion Company in Tokaimura [57]. Frequency of ring chromosomes obtained by the PCC technique (known as the PCC-ring method), was utilized to assess the radiation dose in these victims who were exposed to both neutrons and $\gamma$-rays. One of the victims received 17 Sieverts (17 Gy) while an exposure of 8 Sieverts is generally considered to be fatal. In a subsequent study, both prematurely condensed ring chromosomes and conventional metaphase chromosomes were analyzed for determining the persistence of chromosomal aberrations. Distribution of aberrations in the cells of two patients showed a slight over dispersion pattern presumably resulting from non-uniform exposures. The half-lives of PCC-rings and conventional rings were found to be 8.5 and 8.7 months respectively, which were much shorter compared to that of dicentric chromosomes ( 13.5 months) indicating these half-live values for rings and dicentrics may be of use in retrospective biodosimetry [58]. A new biodosimetry method was proposed by Pouget et al. [59] where fibroblasts derived from human skin biopsies were successfully utilized for radiation dose assessment using the PCC technique. The authors utilized this method for analyzing the skin fibroblasts derived from ex vivo irradiated skin biopsies and from the in vivo irradiated skin biopsy of a victim of the Georgian radiological accident. Frequency of excess chromosome fragments was determined by PCC-FISH using chromosome 4 specific DNA probe on fibroblasts derived from the removed wounded skin tissue of the patient. The skin samples were divided into 41 pieces of 2 to $4 \mathrm{~cm} 2$ identified squares out of which 18 were used for PCC-FISH. Using the calibration curve generated from ex vivo $\gamma$ - rays $\left({ }^{137} \mathrm{Cs}\right.$-source; $1,3,5,8$ and $10 \mathrm{~Gy}$ at a dose rate of $\left.60 \mathrm{~Gy} \mathrm{~h}-{ }^{1}\right)$ irradiated skin fibroblasts, radiation doses below or equal to 3.4 Gy were estimated for less exposed zones, 5-6.5 Gy on the side of the body. Fibroblasts derived from the skin sections corresponding to the back of the body appeared to be most highly exposed with estimated radiation doses in the range of 11.6 Gy to 21 Gy. Application of the PCC-FISH technique on skin fibroblasts may be useful for the biodosimetric analysis of radiation victims with highly localized exposures. Three different cytogenetic techniques [conventional metaphase chromosome analysis, PCC and cytokinesis blocked micronucleus assay (CBMN)] were utilized to estimate the absorbed radiation dose in five victims of the Shanxi Taiyuan radiation accident in China. The estimated radiation doses based on the frequencies of dicentric chromosomes and rings were $12.4 \mathrm{~Gy}, 3.4 \mathrm{~Gy} 2.5 \mathrm{~Gy}, 2.4 \mathrm{~Gy}$ and $2.2 \mathrm{~Gy}$ for the five victims respectively. Interestingly, radiation doses estimated by both PCC and CBMN assays corresponded well with the conventional assay on dicentrics and rings [60]. Using a combination of PCC and FISH techniques, George et al. detected a significantly increased frequency of chromosome exchange aberrations in the crewmembers of long-term Mir missions [61].

In addition to radiation biodosimetry, detection of dicentric chromosomes by FISH using chromosome specific centromeric DNA has been demonstrated for clinical cases. Petkovic et al. [62] detected the existence of a dicentric $X$ chromosome in a girl with moderate growth retardation. Dicentric chromosome resulting from the telomere fusion of chromosomes 20 and 22 is demonstrated to be a recurrent feature of myelodysplastic syndrome and acute myeloid leukaemia patients $[63,64]$. These studies demonstrate that dicentric chromosome may serve as a diagnostic marker for certain types of malignancies. FISH using a pan centromeric probe is gaining in popularity and it has the potential to become the method of choice for radiation biodosimetry in the future owing to its sensitivity and accuracy for dicentric chromosome detection. 


\section{FISH Based Detection of Chromosome Translocations for Retrospective Biodosimetry}

Mis-rejoining of IR induced DNA double strand breaks results in two types of chromosomal aberrations both in vivo and in vitro: (I) unstable or asymmetrical aberrations and (II) stable or symmetrical aberrations. Similar to dicentric chromosome formation, translocation events are proportional to the radiation dose and they persist much longer than dicentric chromosomes in peripheral lymphocytes. Chromosome translocations, particularly reciprocal translocations, can be used for retrospective biodosimetry owing to their long time persistence after IR exposure [65-69]. Clinical laboratories routinely use the Giemsa banding technique to analyze chromosome translocations but this technique requires substantial skill and expertise. As increased frequencies of chromosome translocations are induced at radiation doses higher than $2 \mathrm{~Gy}$, G-banding analysis is very tedious to perform as it involves the karyotyping of each metaphase cell. This technical limitation was circumvented by the emergence of various FISH methods in the 1990s for labeling and detection of DNA probes specific for centromeres or whole chromosomes with fluorophores $[70,71]$. Ried et al. [72] used a combinatorial labeling method to visualize multiple human chromosomes and chromosome specific centromeres simultaneously. Ease of generation of whole chromosome specific paints either by PCR or cosmid clones for FISH has enabled the detection of chromosome translocation events efficiently and rapidly. Using chromosome specific DNA probes, Natarajan et al. [73] demonstrated a higher induction of chromosome translocations than dicentric chromosomes after X-rays exposure of human lymphocytes. FISH using whole chromosome specific DNA probes has opened up new possibilities for monitoring not only radiation workers but also accidentally exposed human population. It was realized that a new system of nomenclature was required for scoring IR induced chromosomal aberrations because FISH methodology using chromosome specific paints yielded complex exchange patterns. Savage and Tucker [74] proposed a system known as "PAINT" (Protocol for Aberration Identification Nomenclature Terminology) after gaining inputs from an international group of cytogeneticists experienced in chromosome painting. The methodologies used for formation, identification and distribution of IR induced chromosomal aberrations have been described in a review [75]. Prior to PAINT, another system of classification known as CAB (C-number of chromosomes involved; Anumber arms involved and B- postulated number of DNA double strand breaks involved) was introduced to analyze complex exchanges $[76,77]$. CAB is based on the positional arrangement of postulated DNA double strand breaks along the chromosome arms.

Bauchinger et al. [78] utilized the whole chromosome painting probes for chromosomes 1, 4 and 12 to measure stable chromosomal translocations in a Techa River (located 7-148 km from the site of radioactive liquid waste release from plutonium processing plant in Mayak, Russia) population exposed to both external ( $\gamma$ - rays) and internal $\left({ }^{90} \mathrm{Sr}\right.$ and $\left.{ }^{137} \mathrm{Cs}\right)$ radiation. FISH analysis revealed a significantly elevated level of translocations in all the 73 exposed residents relative to 39 non-exposed individuals with the estimated dose ranging from 0.24-0.54 Gy. Lindholm et al. [79] analyzed the blood samples of 5 individuals after the accidental whole body $\gamma$-rays exposure in Estonia by FISH using the probes specific for chromosomes 1, 4 and 12 . The results indicated the persistence of stable translocations over a two-year period after exposure suggesting the potential use of translocations for retrospective biodosimetry. Several cytogenetic follow up studies using FISH have been published on retrospective biodosimetry in radiation-exposed victims of Chernobyl $[6,80-82]$ and Goiania [8, 9, 83]. Camparoto et al. [9] demonstrated that chromosome 16 is more 
prone to radiation-induced rearrangement both in the victims of Goiania and in ex vivo irradiated human lymphocytes suggesting that chromosome 16 may have hot spots for IR induced breakage. According to a review by Edwards et al. [67], translocations resulting from a lifetime dose to red bone marrow from a low LET radiation of $0.5 \mathrm{~Gy}$ above normal background can be measured. Certain considerations are necessary for chromosome translocation based retrospective biodosimetry [84]. The baseline frequency of chromosome translocations dramatically varies as a function of age and due to possible exposure to agents other than IR [79]. These two factors may impair the accuracy of radiation dose assessment. Further, information on past radiation exposure is critical without which retrospective radiation dose assessment may not be reliable. Gregoire et al. [85] analyzed the blood samples of 42 patients with suspected past IR overexposure by FISH using a cocktail of three chromosomes (2, 4 and 12). Radiation dose estimated by chromosome translocation was significantly different from $0 \mathrm{~Gy}$ in 25 of the 42 cases and the lowest positive dose estimated was $0.3 \mathrm{~Gy}$. Representative pictures for FISH based detection of chromosomal aberrations in human peripheral blood lymphocytes following X-rays exposure using DNA probes specific for chromosomes 1, 2 and 4 are shown in Figure 4. Chromosome specific DNA probes are available for mouse, rat and hamsters from a wide variety of commercial sources. These probes are extensively used for monitoring the chromosomal damage following exposure to a wide variety of clastogens and carcinogens both in vivo and in vitro. In the FISH methodology, translocation frequencies detected by a cocktail of 3 chromosomes are usually converted to genome equivalent of 46 chromosomes using the formula described by Lucas et al.[86] [Fp = 2.05fp (1-fp) FG, relating the translocation frequency, Fp, measured using FISH to the genomic translocation frequency, $\mathrm{FG}$, where $\mathrm{fp}$ is the fraction of the genome covered by the composite probe]. Conversion of translocation frequency to genome equivalent may have a large statistical uncertainty if translocations occur in a non-random manner involving certain chromosomes more than others after radiation exposure. One drawback of FISH using chromosome specific probes is that the sites of chromosome breakage for translocations cannot be mapped.
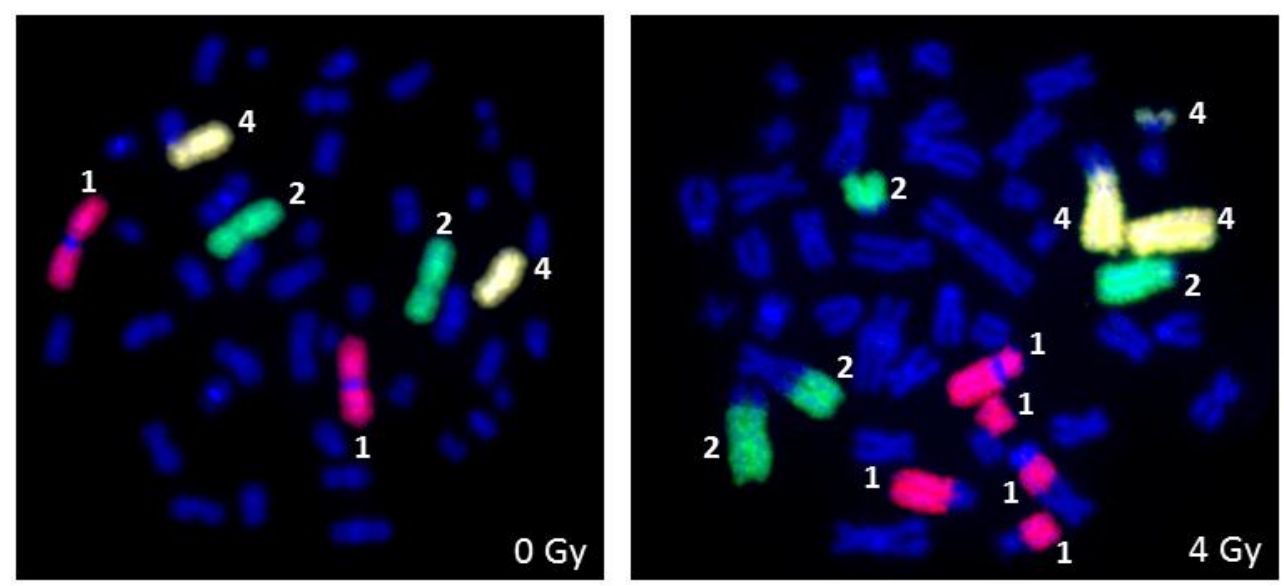

Figure 4 Detection of ionizing radiation induced chromosomal aberrations by FISH using whole human chromosome specific paints for chromosomes 1, 2 and 4 following ex vivo irradiation of human peripheral blood lymphocytes with $4 \mathrm{~Gy}$ of X-rays.

In the past, chromosome specific DNA probes were constructed for mouse from flow sorted metacentric chromosomes arising from the translocation of chromosomes 1, 11 and 13. DNA 
isolated from the flow sorted chromosomes was amplified by PCR using the linker/adaptor method after digestion with the restriction enzyme EcoRI [87]. These probes were initially used for detecting X-rays induced translocations. A similar approach was used by us to generate chromosome specific probes for Chinese Hamster cells [88] to analyze spontaneous chromosome rearrangements. Currently chromosome specific probes are commercially available for a wide variety of mammalian species.

\section{Multicolor FISH for Genome Wide Detection of Chromosomal Aberrations}

Development of spectral karyotyping (SKY) and multicolor FISH (mFISH) techniques using combinatorial labeling of DNA probes with five different fluorochromes for the entire human chromosome complement has advanced the field of radiation cytogenetics. One major advantage of multicolor FISH (the generic name is $\mathrm{mFISH}$ ) is that conversion of translocation frequency to genome equivalent is not required alleviating most of the statistical uncertainties associated with genome equivalent conversion. Complex exchange events, which involve more than two chromosomes, are often not detected by chromosome painting method and therefore whole genome equivalency conversion based on a few chromosomes may not yield acceptable results.

Detection of complex chromosome exchanges by the mFISH and SKY techniques profoundly changed the way these aberrations are classified based on FISH using a few chromosome specific paints. Loucas et al. [89] compared the three color chromosome painting with mFISH to determine the validity of conversion of exchange events to whole genome equivalency. In the $\mathrm{mFISH}$ technique, chromosome specific DNA fragments are labeled by PCR either singly or in combination with five fluorochromes (Fluorescein isothiocyanate, DEAC, Spectrum Orange, Texas Red and Cy5) in varying proportions. Similar to $\mathrm{mFISH}$, SKY uses a combination of chromosome specific probes generated by degenerate oligo primed-PCR amplification of flow sorted chromosomal DNA labeled with five different fluorochromes (Rhodamine, FITC, Texas Red, Cy 5 and Cy5.5) either singly or in combination. SKY utilizes Fourier spectroscopy, charge-coupled-device (CCD) and optical microscopy to capture the spectrum of all the pixel intensities of fluorochromes. Computation software gives the color code for each of the chromosome pair based on pixel intensities. A representative human karyotype labeled with the $\mathrm{mFISH}$ technique is shown in Figure 5. Each chromosome pair is given a computer generated pseudo color based on the pixel intensities of either single or multiple (two or more in combination) fluorochromes. Simple and complex chromosome translocations can be easily scored based on the color code of individual chromosomes. The mFISH technique is quite widely used in both basic and clinical research for identifying the derivative chromosomes. Liehr et al. [90] reviewed the applications of $\mathrm{mFISH}$ in the field of clinical diagnostics and $\mathrm{mFISH}$ has been found useful in detecting genome wide complex chromosomal changes in myelodysplastic syndrome (MDS) and acute myeloid leukaemia [91], esophageal squamous cell carcinomas [91-93], small lymphocytic lymphoma [94, 95] and acute lymphocytic leukaemia [96]. Karst et al. [97] utilized the mFISH technique to detect novel cryptic arrangements involving chromosomes 9,11 and 12 in some patients of acute lymphocytic leukaemia. 


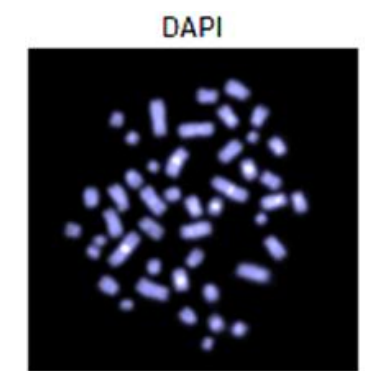

Texas Red

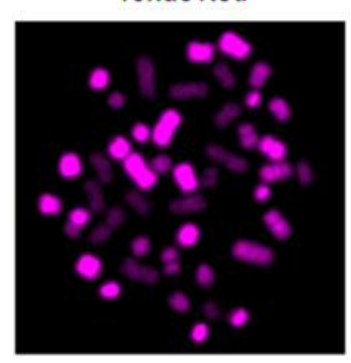

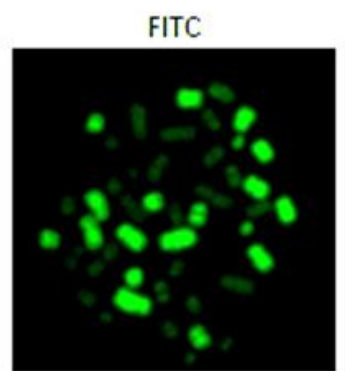

Cy5

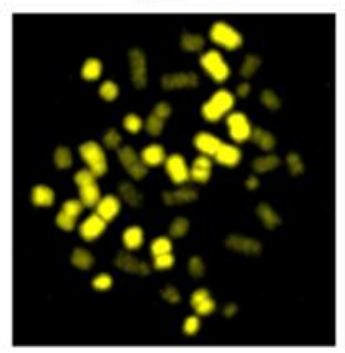

Spectrum Orange

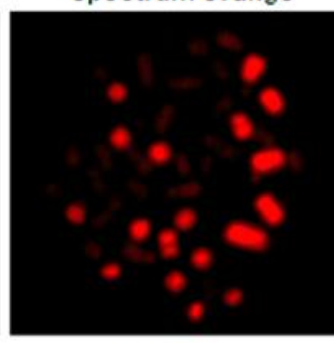

DEAC

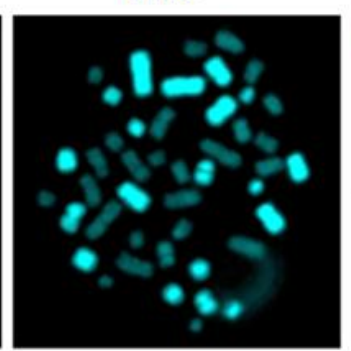

Processed color

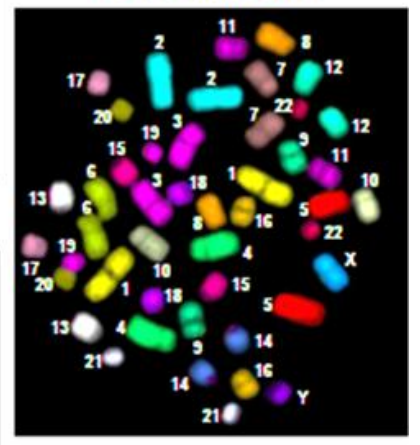

Figure 5 The multicolor FISH ( $\mathrm{mFISH}$ ) technology involves the labeling of chromosome specific DNA fragments by PCR either singly or in combination with five fluorochromes (Fluorescein isothiocyanate, DEAC, Spectrum Orange, Texas Red and Cy5) in permutation and combination. The human chromosomes labeled with each of the 5 fluorochromes are shown. Each chromosome pair is given a computer generated pseudo color based on the pixel intensities of either single or multiple (two or more in combination) fluorochromes.

In addition to clinical diagnostics, the mFISH technique has completely revolutionized the genome wide analysis of IR induced chromosomal exchange events, which are usually not detected by FISH using a cocktail of three chromosome specific DNA probes. Further, the mFISH technology has greatly assisted in distinguishing different radiation qualities based on the comparison of ratios for different chromosome exchange events ([98-101]; Table 1). One of the earliest reports was published by Greulich et al. [102] who tested the utility of mFISH on two model systems: (I) human peripheral blood lymphocytes exposed to $3 \mathrm{~Gy}$ of photons ex vivo and (II) hematopoietic progenitor cell colonies derived from a victim of Chernobyl incident 9 years after in vivo exposure to 5.4 Sievert ( $1 \mathrm{~Sv}=100 \mathrm{rem}$; Roentgen equivalent man, a unit of radiation dosage). In ex vivo irradiated human lymphocytes, as many as 15 chromosomes were found to be involved in chromosome exchange events. In contrast, stable hematopoietic progenitor cells derived from the radiation victim showed the involvement of 3 different chromosomes. Loucas and Cornforth [103] analyzed the complex chromosomal exchanges induced by 4 Gy of $\gamma$-rays in human lymphocytes by $\mathrm{mFISH}$ and found that approximately $50 \%$ of the irradiated cells displayed at least one complex exchange arising from the mis-rejoining of 3 to 11 postulated DNA double strand breaks. A modified version of mFISH known as COBRA-MFISH was described by Darroudi et al. [104] which was based on COmbined Binary RAtio labeling. Unlike mFISH, COBRA-MFISH utilized only four fluorochromes: diethyl-aminocoumarin, Cy3, Cy5 and fluorescein as binary label [105]. The three fluorochromes were used in a pair-wise combination for ratio labeling of 12 chromosomes and the second set of 12 chromosomes was labeled essentially as before but with fluorescein as a binary label. The COBRA-MFISH technique was used to determine the frequencies of both unstable and stable chromosome aberrations in human lymphocytes following exposure to X-rays 
(low LET; 1 and 4 Gy) and neutrons (high LET; 0.25 and 0.5 Gy). The ratio of translocations to dicentrics was approximately equal for $1 \mathrm{~Gy}$ of X-rays but 1.8 fold higher for $4 \mathrm{~Gy}$ of X-rays indicating that the formation of translocations exceeds that of dicentrics in a radiation dose dependent manner. As expected, frequencies for complex translocations detected by COBRAMFISH were much higher for neutrons (40\% of the cells for 0.25 and $0.5 \mathrm{~Gy}$ of neutrons) than Xrays ( $<3 \%$ of the cells for $1 \mathrm{~Gy}$ of $X$-rays). The value of relative biological effectiveness (RBE) for neutrons relative to $X$-rays was 10 for a dose of $0.1 \mathrm{~Gy}$ and 5 for doses of 0.25 and $0.5 \mathrm{~Gy}$. There were no significant differences in the frequencies of simple chromosome translocations between $X$-rays and neutrons. These observations clearly indicate that complex chromosome exchanges (inter-chromosomal exchanges) were most efficiently induced by high LET radiation. In support of this notion, Hande et al. [106] using the mFISH technique, detected a significantly elevated level of complex chromosomal aberrations (involving more than two chromosomes) in healthy former nuclear-weapons workers with a high level of plutonium (an $\alpha$-particle emitter) exposure relative to workers with $\gamma$-rays exposure alone. These workers got exposure to plutonium, $\gamma$-rays or both at the Mayak nuclear weapons complex in Russia several years ago. Plutonium-239, which emits $\alpha-$ particles, is not particularly dangerous as an external radiation source but is really harmful when ingested and can cause cancer. Plutonium dose to the bone marrow ranged from 0.4-2.1 Gy with a mean value of $1.1 \mathrm{~Gy}$ and $\gamma$-rays dose to the bone marrow ranged from 0-3.1 Gy with a mean of 1.5 Gy. The age of the workers ranged from 67-82 and the frequency of complex chromosome exchanges detected by mFISH correlated well with the estimated bone marrow dose. Although these workers had the occupational plutonium exposure during the span of 20 years from 1951 to 1971 , it was estimated that an average of $50 \%$ of the current dose was deposited in their bone marrow after 1983, 25\% after 1993 and 8\% after 1998. Interestingly, frequency of simple chromosome translocations arising from two breaks involving any heterologous pair of chromosomes did not differ among the workers irrespective of the exposure to different radiation qualities. Persistence of complex chromosomal exchanges induced by high LET radiation in Mayak workers suggests their potential use as "cytogenetic fingerprint" for the past exposure of densely ionizing radiation. However, realistic use of stable complex chromosomal exchanges for retrospective biodosimetry requires appropriate dose response curves for different radiation qualities. Representative pictures for complex chromosomal exchanges induced by 4 Gy of X-rays in ex vivo irradiated human lymphocytes are given in Figure 6.

Anderson et al. [107] tested the feasibility of using chromosome insertion as a potential biomarker for chronic high LET radiation by comparing the transmissible and non-transmissible complex chromosome aberrations induced by $\mathrm{X}$-rays and $\alpha$-particles. All the transmissible complex chromosome exchanges analyzed by mFISH contained at least one insertion. One downside of using insertion as a biomarker is its low induction frequency. Wahab et al. [108] analyzed the blood samples of some of the nuclear test veterans of New Zealand who were stationed between 20 and 150 nautical miles from ground zero for the code named Operation Grapple in the midpacific during 1957-58. The chromosomal abnormalities detected recently by mFISH were significantly higher in these veterans ( 275 translocations and 12 dicentrics in a total of 9,360 cells) compared to age matched controls (96 translocations and 1 dicentric chromosome in 9,548 cells). 


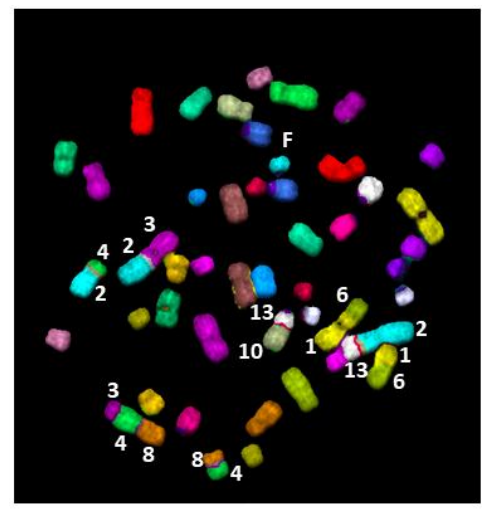

Chromosome 2

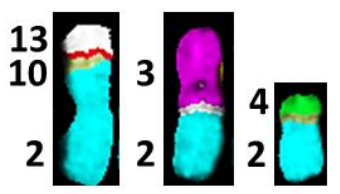

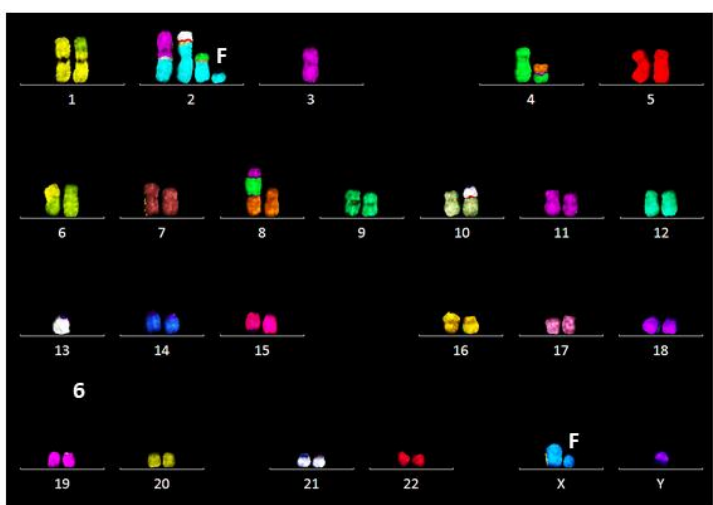

Chromosome 4

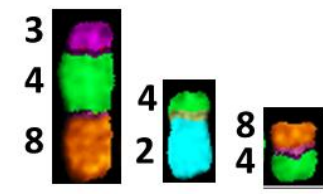

Figure 6 Detection of complex interchromosomal exchanges (involvement of two or more chromosomes) by mFISH in human peripheral lymphocytes irradiated with $4 \mathrm{~Gy}$ of X-rays. Examples of complex exchanges involving chromosomes 2 and 4 are shown. Complex chromosome exchanges are detected with precision by the $\mathrm{mFISH}$ technique.

The aforementioned studies clearly demonstrate that both simple and complex chromosomal exchanges detected by mFISH can be useful for retrospective biodosimetry if suitable calibration curves are available. Using the mFISH technique, persistence of chromosomal damage was recently reported [109] in a patient who received two rounds of radioiodine therapy for his thyroid cancer in 1992 and 1994. Both reciprocal (31) and non-reciprocal translocations (26) were detected in $8.83 \%$ of the cells analyzed ( 57 translocations in a total of 600 cells). Chromosomes 1 , 2, 3 and 4 were found to be involved in 36 of 57 translocations with other chromosomes. The $\mathrm{mFISH}$ technique is used not only for the analysis of IR induced chromosomal aberrations but also for determining the chromosomal instability in cells of cancer patients. Persistence of ring chromosome 8 was reported in $25 \%$ of the lymphocytes in a patient who initially received chemotherapy of 5 cycles of fluorouracil/folic acid for sigmoid colon carcinoma in 2003 followed by radiation therapy for prostate cancer in 2006 [110]. The cytogenetic testing was done on this patient in 2009 and 2012 and the frequency of rings observed in 2009 was 25\%, which was slightly increased to $30 \%$ in 2012 . Persistence of rings is surprising because rings belong to the category of unstable chromosomal aberrations. The authors suggested that the clonal expansion of damaged hematopoietic stem/progenitor cells might be responsible for the long-term persistence of rings in this 84-year-old patient. Although the mFISH technique has greatly increased the analytical power for spontaneous and IR induced complex chromosomal exchanges, its resolution is limited to only 10 mega base pairs of DNA. Additional techniques with higher sensitivity and resolution are needed to identify and characterize the genes that are transposed/altered due to these complex chromosome changes after radiation exposure. Nevertheless, the mFISH technique is useful for detecting a wide range of stable (simple and complex exchanges including insertions) and unstable chromosome aberrations (dicentrics, rings and fragments) that are induced either spontaneously or after exposure to DNA damaging agents. 


\section{Multicolor Band for Detection of Intrachromosomal Changes}

The mFISH technique is very useful for detecting interchromosomal exchanges (simple and complex chromosome translocations) but it is not suitable for the analysis of intrachromosomal changes such as inversions, which are induced by high doses of both low and high LET radiation. Chromosome arm specific probes ( $p$-arm and q-arm) developed in the 1990s were initially used to detect IR induced inter-arm exchanges occurring between the $p$ - and $q$-arms including the centromeric region. Following X-rays exposure of human lymphocytes ( $2.5 \mathrm{~Gy}$ ), the ratio of centric rings to pericentric inversions detected by arm specific probes for human chromosomes 1 and 3 was found to be about 1 but the " $F$ " ratio of intrachromosomal changes to interchromosomal changes ranged from 6-9 (Natarajan et al., 1996). Interestingly, the frequency for intra-arm exchanges was 8.7 fold higher than interchromosomal exchanges (" $\mathrm{H}$ " ratio) considering the DNA content of chromosomes 1 and 3 and a random distribution of aberrations in the genome. Pignalosa et al. [111] compared the frequencies of inter- and intrachromosomal changes in the progeny of human lymphocytes after heavy iron ion exposure and determined the persistence of complex inter-chromosomal exchanges in surviving cells. It appears that the decline of " $F$ " ratio after high LET radiation exposure is due to an increase in complex inter-chromosomal exchanges. Chromosome arm specific probes are useful for detecting inter-arm exchanges but not intra-arm exchanges that occur within a single chromosome arm (paracentric inversions that do not involve the centromeric region). Spatial organization of chromosomes in the interphase nucleus seems to promote more intrachromosomal changes than interchromosomal changes owing to a close proximity of the two arms of the chromosome [112]. This notion needs to be validated by other molecular techniques with a higher resolution and sensitivity for probing the proximity of chromosomes relative to each other. Knowledge of spatial relationship of chromosomes in the interphase nucleus will be useful for understanding the mechanism(s) for complex chromosomal exchanges and their impact on genomic instability and disease outcome.

Development of chromosome specific mBAND probes by Chudoba et al. [10] overcame the limitation of chromosome arm specific probes in detecting intra-arm exchanges. For the generation of chromosome specific mBAND probe, several overlapping micro dissection libraries for chromosome 5 were used. These fragments of approximately 10 mega base pair DNA are labeled with combinatorial labeling of five fluorochromes by PCR to generate bands of multiple colors. The overall labeling scheme for chromosome specific mBAND probes is similar to that of mFISH probe. As each chromosome pair is banded with multiple colors, any disruption in the sequence of colored bands owing to paracentric (within the chromosome arm) or pericentric (between the chromosome arms) inversions can be easily analyzed. A typical labeling scheme used for the generation chromosome 5 specific mBAND (MetaSystems) probe is shown in Figure 7.

It is well known that the complexity of inter- and intrachromosomal aberrations depends on radiation quality (low or high LET), radiation dose, dose-rate and track structure per unit of dose $[12,13,100,113-116]$. Earlier studies have demonstrated that high LET radiation induced biological effects on gene inactivation, cell death, cataracts and carcinogenic events are several folds higher than that observed for low LET radiation [12, 117-125]. Both radiation qualities (low and high LET) induce DSBs but their proportion and complexity are distinctly different from each other. High LET radiation such as neutrons, $\alpha$-particles, carbon ions and heavy iron ions generates clustered DNA lesions encompassing double strand break, single strand break and oxidized base 
damage in a short helical region of DNA. Clustered DNA damage reduces the access of DNA repair machinery so lesions including complex DNA double strand breaks are either left unrepaired or mis-repaired. Persistence of such mis-repaired clustered lesions can lead to malignant transformation and cancer through generation of complex chromosomal aberrations. In support, murine astrocytes irradiated with heavy iron ions were demonstrated to be potently tumorigenic in nude mice xenografts compared to $\gamma$-rays. Further, murine astrocytes after heavy ion exposure displayed stable Robertsonian type translocations involving centromeric fusion of most of the chromosomes in the complement [126].
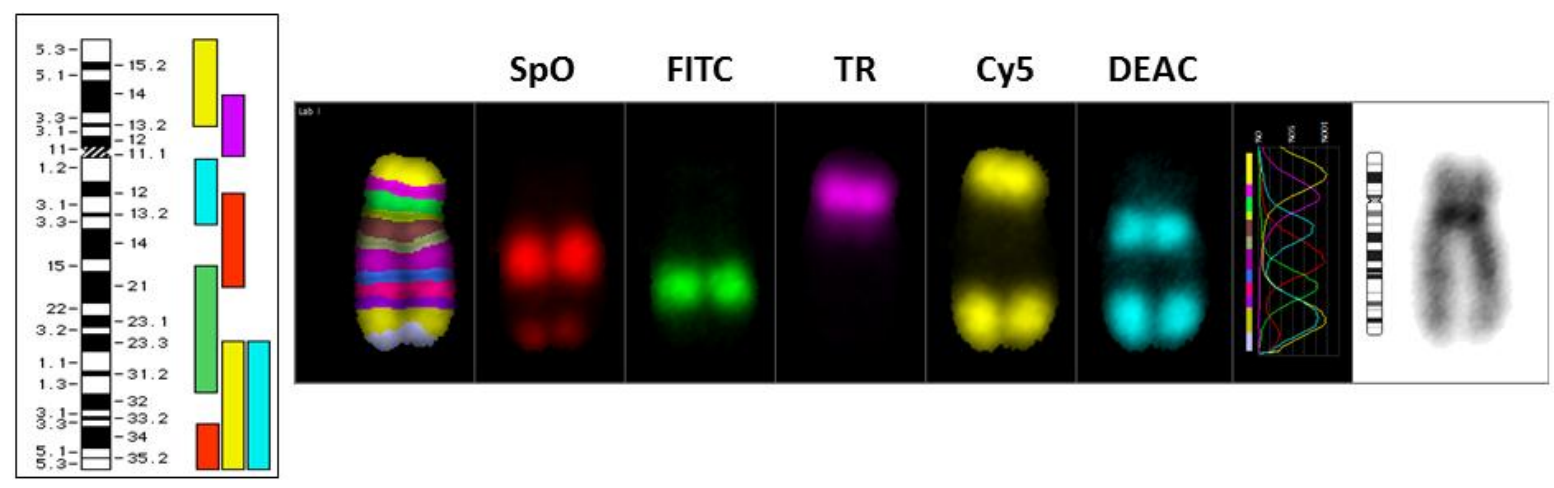

Figure 7 Labeling scheme used for chromosome 5 specific multicolor bands (mBAND) and the labeling pattern of overlapping fragments with each of the 5 fluorochromes along the entire length of chromosome 5 are shown. The high resolution banded appearance of chromosome 5 enables the detection of chromosome inversion events (pericentric and paracentric inversions) after radiation exposure.

An earlier study using the mBAND technique demonstrated the persistence of intrachromosomal changes in healthy nuclear weapon workers who were exposed to high levels of plutonium several years after the radiation exposure [14, 127]. Most strikingly, the extent of intrachromosomal exchanges detected in these workers correlated well with the postulated plutonium dose in the red bone marrow. Earlier biophysical modeling studies predicted that the value for $\mathrm{F}$ ratio (interchromosomal /intrachromosomal changes) decreases while the value for $\mathrm{G}$ ratio (Intra-arm/inter-arm changes) increases following exposure to densely ionizing radiation such as neutrons. Johannes et al. [128] reported that the frequencies of inter- and intrachromosomal changes as well as inter- and intra-arm changes were not drastically different between low (4 Gy of X-rays) and high ( 2 Gy of neutrons, 1 and 2 Gy of heavy ions) LET radiation using the mBAND probe for chromosome 5. However, the ratio of complex to simple interchanges ( $C$ ratio) was found higher for high LET radiation as compared to X-rays and the authors suggested that the $C$ ratio should therefore be considered for biophysical modeling studies. Tawn et al. [129] demonstrated a much higher induction of intrachromosomal changes by $\alpha$-particles relative to $\gamma$ rays. Using sister chromatid differentiation technique, Cartwright et al. [130] reported the dependence of both radiation quality and chromatin structure on inversion frequencies in $\mathrm{CHO}$ cells. Using directional genomic hybridization, Ray et al. [131] found that chromosome 3 inversions were found to be higher for high LET radiation than low LET radiation. Using chromosome 3 specific mBAND in human mammary epithelial cells, Hada et al., [11] documented that the fraction of intrachromosomal changes induced by secondary neutrons was much higher than $\gamma$-rays but the 
inversion frequencies were indistinguishable between the two radiation types. The reason for this discrepancy is not entirely clear. It is likely that DNA repair characteristics of immortalized human mammary epithelial cells may be uniquely different from lymphocytes due to differences in chromatin structure, inherent proliferation capacity and cell cycle duration. Pignalosa et al. [132] reported the induction of chromosome inversions in prostate cancer patients following exposure to X-rays and carbon ions. Using a combination of $\mathrm{mFISH}$ and $\mathrm{mBAND}$ probes, chromosome aberrations and chromosome breakage sites on chromosome 1 were studied by Berardinelli et al. [101]. The chromosome breaks induced by different radiation qualities (1 Gy of X-rays, $(28 \mathrm{keV} / \mu \mathrm{m})$, helium-ions $(62 \mathrm{keV} / \mu \mathrm{m})$ and carbon-ions (96 and $252 \mathrm{keV} / \mu \mathrm{m})$ were located on a region spanning from $1 \mathrm{p} 11.2$ to $1 \mathrm{p} 22.1$ which contains both early and late replicating chromatin. Further, the ratio of complex to simple chromosome exchanges induced by IR exposure depends on LET. A recent review summarizes the role of radiation track structure on the yield of simple and complex chromosomal aberrations [133].

Application of mBAND is also gaining importance in clinical diagnostics. A double inversion of chromosome 6 was detected [134] in a 4-year-old female patient with several prominent pathological features: microcephaly, mental retardation, brachydactyly, bridged palmar crease, and hypertonia. Her karyotype prepared from the blood lymphocytes revealed 46, XX with two translocations involving chromosomes 1 and 12 [t $(1 ; 12)(p 22.3 ; q 21.3)], 7$ and 18 [t (7; 18)(q11.2; q21.2)] and an inversion-involving chromosome 6 [inv (6)(p24q23),] in all the cells. Hu et al. [15] demonstrated complex intrachromosomal rearrangements involving chromosome 6 in a child with dysmorphic features. IR is long known to induce Papillary Thyroid Carcinoma (PTC) and intrachromosomal rearrangements involving chromosome 10 are often associated with formation and progression of PTC. Pignalosa et al. [135] utilized the mBAND technique to analyze the frequency of inversions induced by heavy ions and X-rays on chromosome 10 in human thyroid follicular cells. No significant difference in the frequency of inversions was found between heavy ions and $\mathrm{X}$-rays indicating that high LET radiation may not be more effective than $\mathrm{X}$-rays in the induction of thyroid cancer. However, this may not be valid for in vivo situations because DNA damage response/repair in tissues is much more complex than simple monolayer of cells. Classification of chromosomal aberrations detected by mBAND has proven to be complex and different laboratories use different ways of classifying the aberrations. A unified and wellcharacterized mBAND nomenclature is perhaps required to better categorize different types of inter- and intra-arm exchanges observed by mBAND. Nevertheless, the mBAND technique has provided a much higher resolution than the conventional cytogenetic techniques for the detection and analysis of spontaneous and IR induced intrachromosomal changes.

\section{Interphase FISH for Detecting Chromosome Positioning and Breakage}

Chromosomal aberrations are usually scored in the metaphase chromosomes of human lymphocytes and other cell types. Human lymphocytes are often preferred for assessing the genotoxic effects of DNA damaging agents because blood samples can be easily obtained for analysis by minimally invasive manner. As lymphocytes are largely quiescent and are predominantly in G0/G1 stage of the cell cycle, stimulation for 48 hrs with a mitogen Phytohaemagglutinin (PHA) is required for obtaining metaphase chromosomes. One drawback of this approach is that DNA damage can only be analyzed in metaphase cells obtained from actively 
dividing cells. It is likely that some of the heavily damaged cells may not even reach mitosis or may undergo apoptotic death. An alternate approach is to use interphase cells for monitoring the chromosome breakage by FISH using probes specific for gene loci, centromeres, whole chromosome paints, mFISH and chromosome specific mBAND. As each chromosome is represented twice, two hybridization spots are seen in the interphase nucleus of each somatic cell. Any deviation from the expected number of 2 signals owing to either gain ( $>2$ ) by chromosome breakage or loss due to aneuploidy $(<2)$ can be useful for assessing the extent of DNA damage. Earlier studies detected aneuploidy in the interphase cells by FISH using chromosome specific DNA probes [136, 137]. This approach enables the detection of chromosomal changes induced in different tissues and cells without an elaborate need for metaphase chromosome analysis. Through the use of alpha and classical satellite DNA probes to the centromeric regions of human chromosome 1 (1cen-q12), aneuploidy and chromosome breakage were studied in both unstimulated lymphocytes and granulocytes at $15 \mathrm{~min}$ and $2 \mathrm{hrs}$ after exposure to various doses ( 0 Gy, 1 Gy, 2 Gy, 3 Gy and 4 Gy) of ${ }^{137} \mathrm{Cs} \gamma$-rays after $48-51$ hrs in PHA stimulated lymphocytes and granulocytes [138]. A dose dependent increase in chromosome breakage was observed in granulocytes, unstimulated lymphocytes, stimulated lymphocytes and metaphase chromosomes and the frequencies were similar in both granulocytes and lymphocytes. Likewise, Prasanna et al. [139] detected a radiation dose dependent induction of chromosome 1 breakage in the interphase nuclei of human lymphocytes. These results indicate the feasibility of assessing IR induced chromosomal damage in non-dividing granulocytes and lymphocytes and this approach is beneficial for segregating the highly exposed from moderately or unexposed human population in the case of radiological or nuclear mass casualty incidents [140].

Rearrangements involving RET oncogene localized on chromosome 10 (10q11.2) has been found to be a frequent event in papillary thyroid carcinomas [141, 142]. Interphase FISH analysis of paraffinized tissue samples derived from 13 post-Chernobyl childhood thyroid tumors revealed differences in the pattern of distribution of RET positive cells in the two groups: short and longer latency of tumor development. Aberrant cells were homogenously distributed in the short latency group (4-8 years) relative to clustering of aberrant cells in the longer latency group (9-12 years). The interphase FISH results suggest a polyclonal development of papillary thyroid carcinoma in radiation exposed children and reinforces the utility of interphase FISH for detecting tumor causing chromosome rearrangements in archived tissues.

Recently, a new method known as HiBA-FISH (high throughput break-apart FISH) was described for detecting rare interphase chromosome breaks and translocations [143]. This methodology combines high throughput imaging with measurement of distance between FISH probes that flank the regions of interest. The authors measured the number of rare chromosome breaks at NPM1ALK gene loci and their translocation frequency in anaplastic large cell lymphoma cells after 25 Gy of $\gamma$-rays radiation exposure. Manual microscopic evaluation is time consuming and laborious and therefore high throughput imaging combined with gene fusion or break-apart probes will be ideal for rapid prognosis or diagnosis of various congenital and acquired human diseases. IR is a wellknown carcinogen. Although various genetic and epigenetic models have been proposed and tested in different experimental model systems, precise molecular events leading to IR induced cancer initiation are far from clear. Availability of a whole battery of gene fusion and break-apart probes for well-known oncogenes provide a unique opportunity to investigate the carcinogenic action of IR in relevant cells and tissues by interphase FISH. Spatial distribution of $A B L$ and BCR 
genes was studied in the interphase nuclei of stimulated and non-stimulated human lymphocytes before and after exposure to IR using dual color FISH [144]. In stimulated lymphocytes both ABL and $B C R$ genes moved towards the nuclear membrane and the spatial distance relative to each other also increased. In 2-8\% of the lymphocytes, $A B L$ and BCR genes were very close to each other. A similar trend was found between c-Myc and IgH genes and the translocation involving these genes have been reported in Burkitt's lymphoma. After radiation exposure, $A B L$ and BCR genes were found in the center of the nucleus and the spatial distance between them became much shorter in both G1 and S-phases. The proximity of these potential oncogenes triggered by IR in the nuclear space may be responsible for initiating the cancer development processes. Increased incidence of leukemia and lymphomas observed in some of the A-bomb survivors suggest that IR can potentially increase some of the oncogenic fusions such as ABL and BCR [145]. It is likely that some of the oncogenic translocations including $A B L$ and BCR can also impair DNA repair efficiency. Burkitt's lymphoma cells with c-Myc and IgH translocation accumulated a high number of potentially lethal DNA double strand breaks both spontaneously and after treatment with cytosine arabinoside (Ara-C). In corroboration with the increased accumulation of DNA double strand breaks, these cells displayed diminished homologous recombination repair activity with a reduced expression level of BRCA2, a tumor suppressor protein. Homologous recombination repair is crucial for the repair of DNA double strand breaks and for the maintenance of chromosomal stability. Reduced expression level of BRCA2, a crucial player in homologous recombination repair pathway, probably explains the spontaneous and Ara-C induced accumulation of DNA double strand breaks [146]. The above example illustrates that the oncogenic fusion event(s) triggered by DNA damaging agents such as IR may compromise transcription and repair activities leading to initiation and progression of carcinogenic events in normal cells. As stated before, dual color and multicolor FISH techniques in the interphase nuclei hold great promise for understanding the chromosomal and gene alterations in the nuclear space and their impact on genomic instability.

Earlier studies suggested that the heterochromatic regions of certain human chromosomes (1, 9, 16 and $Y$ ) are the preferred the sites for breakage and for the origin of stable chromosome rearrangements which can lead to early and late stages of tumor development [147-150]. Heterochromatic regions largely composed of highly repetitive DNA sequences account more than $70 \%$ of the human genome. Earlier studies indicated that DNA strand breaks at the centromeric and pericentric heterochromatin can lead to mutations, delayed chromosomal rearrangements and genomic instability $[151,152]$. Availability of FISH probes for specific chromosome breakpoints will be useful for understanding the carcinogenic action of IR.

Chromosome loss is often noticed in murine and human cells after IR exposure. Interphase FISH using a combination of chromosome specific probes can be effectively used to detect numerical chromosomal alterations induced by IR. Evidence for the delayed onset of chromosome aneuploidy was demonstrated in human fibroblasts after low doses of X-rays exposure [153]. The authors utilized the micronucleus-centromere assay with chromosome ( 1 and 4 ) and centromere specific DNA probes. Increased frequencies of aneuploidy with the loss of chromosomes 1 and 4 were observed as a function of radiation dose in cells harvested at $24 \mathrm{hrs}$ post exposure. In mice, hemizygous deletion on chromosome 2 was detected $24 \mathrm{hrs}$ after IR exposure and $15-25 \%$ of the radiation-exposed mice developed acute myeloid leukemia with $80-90 \%$ of the cancer incidence was accompanied by chromosome 2 deletion [154]. Molecular analysis revealed a minimal deleted 
region on chromosome 2, which harbors a tumor suppressor gene Sfpi1. Similar to loss of chromosomes, copy number changes in genes can also be monitored by interphase FISH. Representative pictures for the loss of important genome surveillance genes such as ATM (ataxia telangiectasia mutated) and a major tumor suppressor gene p53 after radiation exposure in the binucleated human lymphocytes are shown in Figure 8. The foregoing account illustrates how interphase FISH can be effectively utilized to monitor a whole spectrum of gene and chromosomal alterations induced either spontaneously or by DNA damaging agents. Suitable calibration curves for each of the endpoints (chromosome breaks, translocation of gene loci and aneuploidy in interphase cells) need to be developed for different radiation qualities so that they can be used in radiation biodosimetry applications.

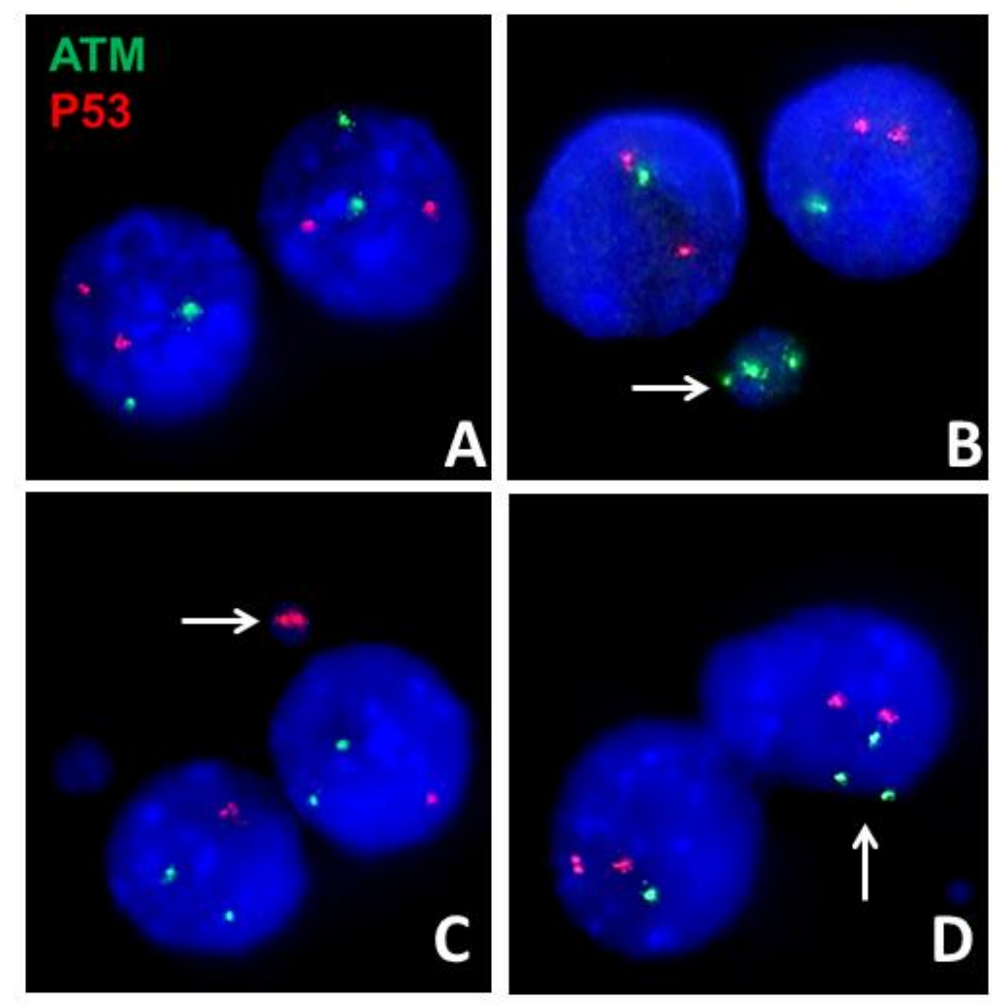

Figure $\mathbf{8}$ Interphase FISH is useful for detecting copy number changes of gene loci in human lymphocytes after radiation exposure. Gene specific probes for ATM (Ataxia telangiectasia mutated) and p53 were used to evaluate the alterations in gene loci in cytokinesis blocked binucleate cells. Binucleate cells were obtained after culturing the lymphocytes for $44 \mathrm{hrs}$ followed by cytokinesis block for an additional $28 \mathrm{hrs}$ in the presence of Cytochalasin B $(5 \mu \mathrm{g} / \mathrm{ml})$. A- Normal binucleate cell with two green fluorescent signals for ATM (green color) and two red fluorescent signals for p53. BNote the presence of only one copy of ATM in both main nuclei and two copies in micronuclei (arrow) after radiation exposure (4 Gy of X-rays). C- Note the presence of only one copy of p53 in both main nuclei and two copies in micronuclei (arrow) after radiation exposure (4 Gy of X-rays). D- Note the mis-segregation of ATM gene loci between two main nuclei, one with 3 copies of ATM (arrow) and the other with one copy. 
It is well known that chromosomes occupy distinct territories in the interphase nucleus and therefore probing the spatial positioning of chromosomes after DNA damage may yield valuable information on chromosome aberration formation. As both unstable and stable aberrations involve intra- or interchromosomal exchanges, the relative positioning of chromosomes relative to each other or proximity in the interphase nucleus is likely to contribute to the nature of aberrations formed: simple and complex. Development of FISH techniques revealed the spatial positioning of chromosomes in the nucleus $[155,156]$. Previous FISH studies suggested that the larger chromosomes are located near the nuclear periphery while smaller chromosomes are positioned at the center of the nucleus in human cells [144, 157-161]. Radial positioning of chromosome domains based on gene density [157, 162-164] was reported for human chromosomes 18 and 19 with the gene-rich chromosome 19 in the interior nuclear position and the gene-poor chromosome 18 in the nuclear periphery despite a gross similarity in size. Using chromosome specific paints, Loannou et al. [165] demonstrated that territories for chromosomes $1,2,3,4,5,7,13,18$ and $Y$ were variable probably owing to different stages of the cell cycle. Some of the chromosome translocations that are characteristic of malignant hemoblastoses are also induced by exposure of human lymphocytes after exposure to fast neutrons [166]. Observation of most significant interchromosomal exchanges involving 14/18, 18/8, 8/3, 1/14, 1/8, 3/18, 3/14 and $9 / 22$ suggests that radiation exposure has the potential to cause malignant transformation of cells through generation of oncogenic chromosome translocations.

The mFISH technique offers a unique opportunity to examine the impact of spatial positioning of chromosomes on IR induced simple and complex chromosome translocations. Using the mFISH technique, chromosomes that are spatially related to each other in peripheral blood lymphocytes have been characterized in the interphase nucleus [167]. Arsuaga et al. [168] identified two clusters of chromosomes $(1,16,17,19,22)$ and $(13,14,15,21,22)$ whose domains were closer to each other than predicted by a random distribution model. Somewhat consistent with this model, enhanced chromosome translocation frequencies involving neighborhood territories associated with chromosomes 1, 3, 4, 7, 10, 14 and 15 were observed in human lymphoblastoid cells after Xrays and neutrons exposure [167]. Detection of simple and complex chromosomal exchanges by mFISH will be useful not only for retrospective biodosimetry but also for monitoring some of the early onset of IR induced oncogenic translocation events and their impact on genomic instability and cancer.

\section{Use of Chromosome Conformation Capture Technique to Determine the Role of Proximity Effects on IR Induced Chromosome Exchange Events}

It is increasingly realized that the higher order organization of chromatin in the nuclear space is crucial for the fidelity of many fundamental metabolic activities of DNA such as replication, transcription, recombination and DNA repair. It is well established that chromosomes occupy specific domains or territories and the proximities of chromosome territories relative to each other in the nuclear space may influence some of the recurrent translocations observed in cancer cells. Earlier studies utilized the FISH technique with a few chromosome specific DNA probes to understand their interphase positioning in the nucleus and their reorganization subsequent to DNA damage induced by chemicals and IR in human cells. Using the mFISH technique, Foster et al. [169], detected non-random exchange events after $\gamma$-rays exposure between certain chromosome 
pairs ( 1 and 13; 9 and 17; 9 and 18; 12 and 18; 16 and 21) that occurred more frequently than expected on a random basis [169]. Although these studies yielded valuable information on territorial organization of chromosomes, low resolution coupled with an inability to analyze genome wide chromosome topology had prompted the scientists to develop innovative technologies to determine the 3-dimensional genomic architecture of normal and cancer cells. Dekker et al. [170-172] described a chromosome conformation capture methodology for detecting the fine structural organization of chromosomes and their changes during the meiotic process in yeast. Briefly, the chromosome conformation capture (3C) methodology involves several steps: (I) crosslinking of chromatin with formaldehyde for creating covalent bonds between DNA, (II) digestion with restriction enzymes of choice (Hind III, BgI II, ECoR I, Dpn I and ACi I), (III) linker mediated ligation of DNA fragments, (IV) reversal of crosslinking and (V) PCR amplification and deep DNA sequencing. In the subsequent years, the $3 C$ methodology and its derivatives were extended to the analysis of mammalian cells $[171,173-176]$. The $3 C$ technique provides the organization of genome at a high-resolution level and is very useful for detecting the spatial interaction between chromosomes and gene loci. Methodologies for $4 \mathrm{C}$ and $5 \mathrm{C}$ were soon developed and in the $4 \mathrm{C}$ technology, isolated cross-linked and labeled DNA fragments are hybridized to microarray or subjected to next generation sequencing. The fundamental difference between $3 \mathrm{C}$ and $5 \mathrm{C}$ lies in the design of primers and the primers used for the $5 \mathrm{C}$ methodology have universal sequence such as T7 and T3 that is appended to the $5^{\prime}$ ends. This modification coupled with multiplex PCR and sequencing allows the detection of sequence interaction even within a single locus. Chromatin interaction analysis by paired end tag sequencing (ChIA-PET) is an improved version of $3 C$ that utilizes chromatin immunoprecipitation assay (ChIP). A combination of ChIP and $3 \mathrm{C}$ helps in identifying genome wide interaction of chromatin with a specific protein of interest. ChIA-PET led to the discovery of many critical proteins such as RAD21, CTCF, SMC3 and ZNF14 that are important for the formation of 3D chromatin structure. $\mathrm{Hi}-\mathrm{C}$ is yet another version of $3 \mathrm{C}$ methodology which uses high throughput sequencing technology and it does not require specific primers but provides a comprehensive knowledge of interaction between chromosome territories and thereby a genome-wide contact maps [177]. Recently, it has been shown that Hi-C methodology can be applied to the analysis of a single cell and this is distinctly advantageous to analyze the extent of inter-cellular heterogeneity, which is quite prevalent in some cancer cells. Collectively, $3 \mathrm{C}$ based technologies have greatly improved our understanding on 3 dimensional architecture of chromosomes and their territories in interphase nucleus. We recently demonstrated the utility of $\mathrm{Hi}-\mathrm{C}$ in the analysis of ionizing radiation induced chromosomal aberrations based on their spatial proximity in the nucleus [167]. These high-resolution techniques can be effectively utilized to develop cytogenetic signatures for predicting high LET radiation induced stochastic effects. Additionally, fine detailed analysis using these methodologies will determine whether some of the human genetic diseases are caused by alterations in 3dimensional organization of chromatin but whether such alterations can serve as fingerprints for the prognosis/diagnosis of various diseases including cancer.

\section{Conclusions}

A PubMed search made using the term "FISH technique in Radiation Biology" yielded 328 publications spanning from 1990 through 2018 indicating the steadily emerging use of FISH 
technique in radiation biology. It is likely that the search might have missed a lot more papers. FISH based methodology for chromosome translocation has greatly advanced the field of retrospective biodosimetry and for long-term monitoring of radiation exposed humans for potential cancer risks. As delayed genomic instability has been amply demonstrated after chronic low dose exposure, FISH technology is going to be instrumental for monitoring the chromosomal changes that lead to tissue degenerative diseases and cancer in radiation exposed victims. As human exposure to IR has become inevitable owing to its increased use in medical diagnostic procedures such as CT and CAT scans, extensive investigation is required to understand the biological effects of low dose radiation. Use of FISH methodology combined with high resolution molecular techniques like Chromosome Conformation Capture technique for probing 3dimensional organization of human genome have given great insights into the spatial organization of chromosomes and how chromosome proximity effects can explain the formation of simple and complex chromosome translocations that arise either spontaneously or through DNA damage accumulation. Future cytogenetic and molecular studies will unravel the complexity and functions of higher order chromatin organization and how alterations in chromatin organization can lead to age associated and IR induced cancer and degenerative diseases.

\section{Acknowledgments}

The financial assistance received from the U.S. Department of Energy (\#DE-AC05-06OR23100 and Technology Integration Grants ORISE-CM-466, ORISE-CM-989 and ORISE-CM-990 from NA-84) is gratefully acknowledged. REAC/TS, an organizational program of the Oak Ridge Institute for Science and Education, is operated by Oak Ridge Associated Universities for the U.S. DOE. The content is solely the responsibility of the author and does not reflect the official views or opinions of the U.S. DOE, ORISE and ORAU.

\section{Author Contributions}

Adayabalam S. Balajee did all the research work of this study.

\section{Competing Interests}

The author has no competing interests to declare.

\section{References}

1. Gall JG, Pardue ML. Formation and detection of RNA-DNA hybrid molecules in cytological preparations. Proc Natl Acad Sci U S A. 1969; 63: 378-383.

2. Pardue ML, Gall JG. Molecular hybridization of radioactive DNA to the DNA of cytological preparations. Proc Natl Acad Sci U S A. 1969; 64: 600-604.

3. Pardue ML, Gall JG. Chromosomal localization of mouse satellite DNA. Science. 1970; 168: 1356-1358.

4. Pardue ML, Gall JG. Nucleic acid hybridization to the DNA of cytological preparations. Methods Cell Biol. 1975; 10: 1-16.

5. Bender MA, Gooch PC. Types and rates of x-ray-induced chromosome aberrations in human blood irradiated in vitro. Proc Natl Acad Sci U S A. 1962; 48: 522-532. 
6. Sevan'kaev AV, Lloyd DC, Edwards AA, Khvostunov IK, Mikhailova GF, Golub EV, et al. A cytogenetic follow-up of some highly irradiated victims of the Chernobyl accident. Radiat Prot Dosimetry. 2005; 113: 152-161.

7. Salassidis K, Georgiadou-Schumacher V, Braselmann H, Muller P, Peter RU, Bauchinger M. Chromosome painting in highly irradiated Chernobyl victims: a follow-up study to evaluate the stability of symmetrical translocations and the influence of clonal aberrations for retrospective dose estimation. Int J Radiat Biol. 1995; 68: 257-262.

8. Camparoto ML, Ramalho AT, Natarajan AT, Curado MP, Sakamoto-Hojo ET. Translocation analysis by the FISH-painting method for retrospective dose reconstruction in individuals exposed to ionizing radiation 10 years after exposure. Mutat Res. 2003; 530: 1-7.

9. Camparoto ML, Takahashi-Hyodo SA, Dauwerse JG, Natarajan AT, Sakamoto-Hojo ET. High susceptibility of chromosome 16 to radiation-induced chromosome rearrangements in human lymphocytes under in vivo and in vitro exposure. Cytogenet Genome Res. 2005; 108: 287-292.

10. Chudoba I, Plesch A, Lorch T, Lemke J, Claussen U, Senger G. High resolution multicolorbanding: a new technique for refined FISH analysis of human chromosomes. Cytogenet Cell Genet. 1999; 84: 156-160.

11. Hada M, Gersey B, Saganti PB, Wilkins R, Cucinotta FA, Wu H. mBAND analysis of chromosome aberrations in human epithelial cells induced by gamma-rays and secondary neutrons of low dose rate. Mutat Res. 2010; 701: 67-74.

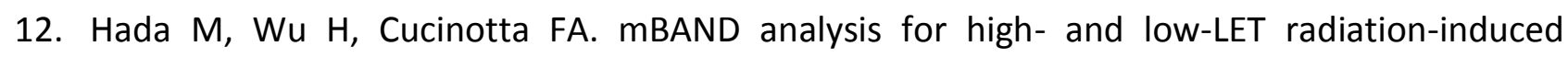
chromosome aberrations: a review. Mutat Res. 2011; 711: 187-192.

13. Hada $M$, Zhang $Y$, Feiveson A, Cucinotta FA, Wu H. Association of inter- and intrachromosomal exchanges with the distribution of low- and high-LET radiation-induced breaks in chromosomes. Radiat Res. 2011; 176: 25-37.

14. Hande MP, Azizova TV, Geard CR, Burak LE, Mitchell CR, Khokhryakov VF, et al. Past exposure to densely ionizing radiation leaves a unique permanent signature in the genome. Am J Hum Genet. 2003; 72: 1162-1170.

15. Hu J, Sathanoori M, Kochmar SJ, Surti U. Application of multicolor banding for identification of complex chromosome 18 rearrangements. J Mol Diagnost. 2006; 8: 521-525.

16. Nugis VY, Filushkin IV, Chistopolskij AS. Retrospective dose estimation using the dicentric distribution in human peripheral lymphocytes. Appl Radiat Isot. 2000; 52: 1139-1144.

17. Sevan'kaev AV, Khvostunov IK, Mikhailova GF, Golub EV, Potetnya OI, Shepel NN, et al. Novel data set for retrospective biodosimetry using both conventional and FISH chromosome analysis after high accidental overexposure. Appl Radiat Isot. 2000; 52: 1149-1152.

18. Natarajan AT, Ramalho AT, Vyas RC, Bernini LF, Tates AD, Ploem JS, et al. Goiania radiation accident: results of initial dose estimation and follow up studies. Prog Clin Biol Res. 1991; 372: 145-153.

19. Natarajan AT, Vyas RC, Wiegant J, Curado MP. A cytogenetic follow-up study of the victims of a radiation accident in Goiania (Brazil). Mutat Res. 1991; 247: 103-111.

20. Ramalho AT, Nascimento AC. The fate of chromosomal aberrations in 137Cs-exposed individuals in the Goiania radiation accident. Health Phys. 1991; 60: 67-70. 
21. Lee JK, Han EA, Lee SS, Ha WH, Barquinero JF, Lee HR, et al. Cytogenetic biodosimetry for Fukushima travelers after the nuclear power plant accident: no evidence of enhanced yield of dicentrics. J Radiat Res. 2012; 53: 876-881.

22. Suto Y. Review of Cytogenetic analysis of restoration workers for Fukushima Daiichi nuclear power station accident. Radiat Prot Dosimetry. 2016; 171: 61-63.

23. Suto $Y$, Hirai $M$, Akiyama $M$, Kobashi $G$, Itokawa $M$, Akashi $M$, et al. Biodosimetry of restoration workers for the Tokyo Electric Power Company (TEPCO) Fukushima Daiichi nuclear power station accident. Health Phys. 2013; 105: 366-373.

24. Deperas J, Szluinska M, Deperas-Kaminska M, Edwards A, Lloyd D, Lindholm C, et al. CABAS: a freely available PC program for fitting calibration curves in chromosome aberration dosimetry. Radiat Prot Dosimetry. 2007; 124: 115-123.

25. Lloyd DC, Purrott RJ, Dolphin GW. Chromosome aberration dosimetry using human lymphocytes in simulated partial body irradiation. Phys Med Biol. 1973; 18: 421-431.

26. Sasaki MS, Miyata H. Biological dosimetry in atomic bomb survivors. Nature. 1968; 220: 11891193.

27. Brame RS, Groer PG. Bayesian methods for chromosome dosimetry following a criticality accident. Radiat Prot Dosimetry. 2003; 104: 61-63.

28. Lloyd DC, Purrott RJ, Reeder EJ. The incidence of unstable chromosome aberrations in peripheral blood lymphocytes from unirradiated and occupationally exposed people. Mutat Res. 1980; 72: 523-532.

29. Bolzan AD, Bianchi MS. Detection of incomplete chromosome elements and interstitial fragments induced by bleomycin in hamster cells using a telomeric PNA probe. Mutat Res. 2004; 554: 1-8.

30. Shi L, Fujioka K, Sun J, Kinomura A, Inaba T, Ikura T, et al. A modified system for analyzing ionizing radiation-induced chromosome abnormalities. Radiat Res. 2012; 177: 533-538.

31. M'Kacher R, Maalouf EE, Ricoul M, Heidingsfelder L, Laplagne E, Cuceu C, et al. New tool for biological dosimetry: reevaluation and automation of the gold standard method following telomere and centromere staining. Mutat Res. 2014; 770: 45-53.

32. Tanaka K, Sawada S, Kamada N. Relative biological effectiveness and dose rate effect of tritiated water on chromosomes in human lymphocytes and bone marrow cells. Mutat Res. 1994; 323: 53-61.

33. Hristova R, Hadjidekova V, Grigorova M, Nikolova T, Bulanova M, Popova L, et al. Chromosome analysis of nuclear power plant workers using fluorescence in situ hybridization and Giemsa assay. J Radiat Res. 2013; 54: 832-839.

34. Ballarini F, Ottolenghi A. Chromosome aberrations as biomarkers of radiation exposure: modelling basic mechanisms. Adv Space Res. 2003; 31: 1557-1568.

35. Hayata I, Tabuchi H, Furukawa A, Okabe N, Yamamoto M, Sato K. Robot system for preparing lymphocyte chromosome. J Radiat Res. 1992; 33 Suppl: 231-241.

36. De Amicis A, De Sanctis S, Di Cristofaro S, Franchini V, Regalbuto E, Mammana G, et al. Dose estimation using dicentric chromosome assay and cytokinesis block micronucleus assay: comparison between manual and automated scoring in triage mode. Health Phys. 2014; 106: 787-797.

37. Gruel G, Gregoire E, Lecas S, Martin C, Roch-Lefevre S, Vaurijoux A, et al. Biological dosimetry by automated dicentric scoring in a simulated emergency. Radiat Res. 2013; 179: 557-569. 
38. Romm H, Ainsbury E, Barnard S, Barrios L, Barquinero JF, Beinke C, et al. Automatic scoring of dicentric chromosomes as a tool in large scale radiation accidents. Mutat Res. 2013; 756: 174183.

39. Schunck C, Johannes T, Varga D, Lorch T, Plesch A. New developments in automated cytogenetic imaging: unattended scoring of dicentric chromosomes, micronuclei, single cell gel electrophoresis, and fluorescence signals. Cytogenet Genome Res. 2004; 104: 383-389.

40. Liu J, Li Y, Wilkins R, Flegal F, Knoll JHM, Rogan PK. Accurate cytogenetic biodosimetry through automated dicentric chromosome curation and metaphase cell selection. F1000Res. 2017; 6: 1396.

41. Rogan PK, Li Y, Wilkins RC, Flegal FN, Knoll JH. Radiation Dose Estimation by Automated Cytogenetic Biodosimetry. Radiat Prot Dosimetry. 2016; 172: 207-217.

42. Shirley B, Li Y, Knoll JHM, Rogan PK. Expedited Radiation Biodosimetry by Automated Dicentric Chromosome Identification (ADCI) and Dose Estimation. J Vis Exp. 2017.

43. Martin PR, Berdychevski RE, Subramanian U, Blakely WF, Prasanna PG. Sample Tracking in an Automated Cytogenetic Biodosimetry Laboratory for Radiation Mass Casualties. Radiat Meas. 2007; 42: 1119-1124.

44. Blakely WF, Carr Z, Chu MC, Dayal-Drager R, Fujimoto K, Hopmeir M, et al. WHO 1st consultation on the development of a global biodosimetry laboratories network for radiation emergencies (BioDoseNet). Radiat Res. 2009; 171: 127-139.

45. Wilkins RC, Romm H, Oestreicher U, Marro L, Yoshida MA, Suto Y, et al. Biological Dosimetry by the Triage Dicentric Chromosome Assay - Further validation of International Networking. Radiat Meas. 2011; 46: 923-928.

46. Kulka U, Ainsbury L, Atkinson M, Barquinero JF, Barrios L, Beinke C, et al. Realising the European Network of Biodosimetry (RENEB). Radiat Prot Dosimetry. 2012; 151: 621-625.

47. Romm H, Ainsbury EA, Barquinero JF, Barrios L, Beinke C, Cucu A, et al. Web based scoring is useful for validation and harmonisation of scoring criteria within RENEB. Int J Radiat Biol. 2017; 93: 110-117.

48. Oestreicher U, Samaga D, Ainsbury E, Antunes AC, Baeyens A, Barrios L, et al. RENEB intercomparisons applying the conventional Dicentric Chromosome Assay (DCA). Int J Radiat Biol. 2017; 93: 20-29.

49. Garcia O, Di Giorgio M, Vallerga MB, Radl A, Taja MR, Seoane A, et al. Interlaboratory comparison of dicentric chromosome assay using electronically transmitted images. Radiat Prot Dosimetry. 2013; 154: 18-25.

50. Sugarman SL, Livingston GK, Stricklin DL, Abbott MG, Wilkins RC, Romm $H$, et al. The Internet's role in a biodosimetric response to a radiation mass casualty event. Health Phys. 2014; 106: S65-70.

51. Wilkins RC, Beaton-Green LA, Lachapelle S, Kutzner BC, Ferrarotto C, Chauhan V, et al. Evaluation of the annual Canadian biodosimetry network intercomparisons. Int J Radiat Biol. 2015; 91: 443-451.

52. Karachristou I, Karakosta M, Pantelias A, Hatzi VI, Karaiskos P, Dimitriou P, et al. Triage biodosimetry using centromeric/telomeric PNA probes and Giemsa staining to score dicentrics or excess fragments in non-stimulated lymphocyte prematurely condensed chromosomes. Mutat Res Genet Toxicol Environ Mutagen. 2015; 793: 107-114. 
53. Gotoh E, Tanno Y. Simple biodosimetry method for cases of high-dose radiation exposure using the ratio of the longest/shortest length of Giemsa-stained drug-induced prematurely condensed chromosomes (PCC). Int J Radiat Biol. 2005; 81: 379-385.

54. Gotoh E, Tanno Y, Takakura K. Simple biodosimetry method for use in cases of high-dose radiation exposure that scores the chromosome number of Giemsa-stained drug-induced prematurely condensed chromosomes (PCC). Int J Radiat Biol. 2005; 81: 33-40.

55. Wang ZZ, Li WJ, Zhi DJ, Gao QX, Qu Y, Wang BQ. Prematurely condensed chromosome fragments in human lymphocytes induced by high doses of high-linear-energy-transfer irradiation. Mutat Res. 2009; 679: 9-12.

56. Wang ZZ, Li WJ, Zhi DJ, Jing XG, Wei W, Gao QX, et al. Biodosimetry estimate for high-LET irradiation. Radiat Environ Biophys. 2007; 46: 229-235.

57. Hayata I, Kanda R, Minamihisamatsu M, Furukawa M, Sasaki MS. Cytogenetical dose estimation for 3 severely exposed patients in the JCO criticality accident in Tokai-mura. J Radiat Res. 2001; 42 Suppl: S149-155.

58. Kanda R, Minamihisamatsu M, Hayata I. Dynamic analysis of chromosome aberrations in three victims of the Tokai-mura criticality accident. Int J Radiat Biol. 2002; 78: 857-862.

59. Pouget JP, Laurent C, Delbos M, Benderitter M, Clairand I, Trompier F, et al. PCC-FISH in skin fibroblasts for local dose assessment: biodosimetric analysis of a victim of the Georgian radiological accident. Radiat Res. 2004; 162: 365-376.

60. Yao B, Li Y, Liu G, Guo M, Bai J, Man Q, et al. Estimation of the biological dose received by five victims of a radiation accident using three different cytogenetic tools. Mutat Res. 2013; 751: 66-72.

61. George $\mathrm{K}, \mathrm{Wu} \mathrm{H}$, Willingham $\mathrm{V}$, Cucinotta FA. The effect of space radiation on the induction of chromosome damage. Phys Med. 2001; 17 Suppl 1: 222-225.

62. Petkovic I, Barisic I, Bago R. Cytogenetic evaluation, fluorescence in situ hybridization, and molecular study of psu idic(X)(pter-->q22.3::q22.3-->pter) chromosome abberation in a girl with moderate growth retardation. Croat Med J. 2003; 44: 494-499.

63. MacKinnon RN, Duivenvoorden HM, Campbell LJ, Wall M. The Dicentric Chromosome $\operatorname{dic}(20 ; 22)$ Is a Recurrent Abnormality in Myelodysplastic Syndromes and Is a Product of Telomere Fusion. Cytogenet Genome Res. 2016; 150: 262-272.

64. Sarova I, Brezinova J, Zemanova Z, Ransdorfova S, Svobodova K, Izakova S, et al. High frequency of dicentric chromosomes detected by multi-centromeric FISH in patients with acute myeloid leukemia and complex karyotype. Leuk Res. 2018; 68: 85-89.

65. Ainsbury EA, Bakhanova E, Barquinero JF, Brai M, Chumak V, Correcher V, et al. Review of retrospective dosimetry techniques for external ionising radiation exposures. Radiat Prot Dosimetry. 2011; 147: 573-592.

66. Beinke C, Meineke V. High potential for methodical improvements of FISH-based translocation analysis for retrospective radiation biodosimetry. Health Phys. 2012; 103: 127132.

67. Edwards AA, Lindholm C, Darroudi F, Stephan G, Romm H, Barquinero J, et al. Review of translocations detected by FISH for retrospective biological dosimetry applications. Radiat Prot Dosimetry. 2005; 113: 396-402. 
68. Kleinerman RA, Romanyukha AA, Schauer DA, Tucker JD. Retrospective assessment of radiation exposure using biological dosimetry: chromosome painting, electron paramagnetic resonance and the glycophorin a mutation assay. Radiat Res. 2006; 166: 287-302.

69. Straume T, Anspaugh LR, Haskell EH, Lucas JN, Marchetti AA, Likhtarev IA, et al. Emerging technological bases for retrospective dosimetry. Stem Cells. 1997; 15 Suppl 2: 183-193.

70. Lichter P, Ward DC. Is non-isotopic in situ hybridization finally coming of age? Nature. 1990; 345: 93-94.

71. Wiegant J, Ried T, Nederlof PM, van der Ploeg M, Tanke HJ, Raap AK. In situ hybridization with fluoresceinated DNA. Nucleic Acids Res. 1991; 19: 3237-3241.

72. Ried T, Landes G, Dackowski W, Klinger K, Ward DC. Multicolor fluorescence in situ hybridization for the simultaneous detection of probe sets for chromosomes $13,18,21, \mathrm{X}$ and $Y$ in uncultured amniotic fluid cells. Hum Mol Genet. 1992; 1: 307-313.

73. Natarajan AT, Vyas RC, Darroudi F, Vermeulen S. Frequencies of X-ray-induced chromosome translocations in human peripheral lymphocytes as detected by in situ hybridization using chromosome-specific DNA libraries. Int J Radiat Biol. 1992; 61: 199-203.

74. Savage JR, Tucker JD. Nomenclature systems for FISH-painted chromosome aberrations. Mutat Res. 1996; 366: 153-161.

75. Obe G, Pfeiffer P, Savage JR, Johannes C, Goedecke W, Jeppesen P, et al. Chromosomal aberrations: formation, identification and distribution. Mutat Res. 2002; 504: 17-36.

76. Savage JR, Simpson P. On the scoring of FISH-"painted" chromosome-type exchange aberrations. Mutat Res. 1994; 307: 345-353.

77. Simpson PJ, Savage JR. Estimating the true frequency of X-ray-induced complex chromosome exchanges using fluorescence in situ hybridization. Int J Radiat Biol. 1995; 67: 37-45.

78. Bauchinger M, Salassidis K, Braselmann H, Vozilova A, PressI S, Stephan G, et al. FISH-based analysis of stable translocations in a Techa River population. Int J Radiat Biol. 1998; 73: 605612.

79. Lindholm C, Tekkel M, Veidebaum T, Ilus T, Salomaa S. Persistence of translocations after accidental exposure to ionizing radiation. Int J Radiat Biol. 1998; 74: 565-571.

80. Khvostunov IK, Snigiryova GP, Moiseenko VV, Lloyd DC. A follow-up cytogenetic study of workers highly exposed inside the Chernobyl sarcophagus. Radiat Prot Dosimetry. 2015; 167: 405-418.

81. Salassidis K, Schmid E, Peter RU, Braselmann H, Bauchinger M. Dicentric and translocation analysis for retrospective dose estimation in humans exposed to ionising radiation during the Chernobyl nuclear power plant accident. Mutat Res. 1994; 311: 39-48.

82. Snigiryova G, Braselmann H, Salassidis K, Shevchenko V, Bauchinger M. Retrospective biodosimetry of Chernobyl clean-up workers using chromosome painting and conventional chromosome analysis. Int J Radiat Biol. 1997; 71: 119-127.

83. Natarajan AT, Santos SJ, Darroudi F, Hadjidikova V, Vermeulen S, Chatterjee S, et al. 137Cesium-induced chromosome aberrations analyzed by fluorescence in situ hybridization: eight years follow up of the Goiania radiation accident victims. Mutat Res. 1998; 400: 299-312.

84. Sigurdson AJ, Ha M, Hauptmann M, Bhatti P, Sram RJ, Beskid O, et al. International study of factors affecting human chromosome translocations. Mutat Res. 2008; 652: 112-121. 
85. Gregoire E, Roy L, Buard V, Delbos M, Durand V, Martin-Bodiot C, et al. Twenty years of FISHbased translocation analysis for retrospective ionizing radiation biodosimetry. Int J Radiat Biol. 2018; 94: 248-258.

86. Lucas JN, Awa A, Straume T, Poggensee M, Kodama Y, Nakano M, et al. Rapid translocation frequency analysis in humans decades after exposure to ionizing radiation. Int J Radiat Biol. 1992; 62: 53-63.

87. Boei JJ, Balajee AS, de Boer P, Rens W, Aten JA, Mullenders LH, et al. Construction of mouse chromosome-specific DNA libraries and their use for the detection of X-ray-induced aberrations. Int J Radiat Biol. 1994; 65: 583-590.

88. Balajee AS, Dominguez I, Natarajan AT. Construction of Chinese hamster chromosome specific DNA libraries and their use in the analysis of spontaneous chromosome rearrangements in different cell lines. Cytogenet Cell Genet. 1995; 70: 95-101.

89. Loucas BD, Shuryak I, Cornforth MN. Three-Color Chromosome Painting as Seen through the Eyes of mFISH: Another Look at Radiation-Induced Exchanges and Their Conversion to WholeGenome Equivalency. Front Oncol. 2016; 6: 52.

90. Liehr T, Weise A, Hamid AB, Fan X, Klein E, Aust N, et al. Multicolor FISH methods in current clinical diagnostics. Expert Rev Mol Diagn. 2013; 13: 251-255.

91. Babicka L, Ransdorfova S, Brezinova J, Zemanova Z, Sindelarova L, Siskova M, et al. Analysis of complex chromosomal rearrangements in adult patients with MDS and AML by multicolor FISH. Leuk Res. 2007; 31: 39-47.

92. Wu YP, Yang YL, Yang GZ, Wang XY, Luo ML, Zhang Y, et al. Identification of chromosome aberrations in esophageal cancer cell line KYSE180 by multicolor fluorescence in situ hybridization. Cancer Genet Cytogenet. 2006; 170: 102-107.

93. Yang $Y$, Chu J, Wu Y, Luo M, Xu X, Han Y, et al. Chromosome analysis of esophageal squamous cell carcinoma cell line KYSE 410-4 by repetitive multicolor fluorescence in situ hybridization. J Genet Genomics. 2008; 35: 11-16.

94. Caraway NP, Thomas E, Khanna A, Payne L, Zhang HZ, Lin E, et al. Chromosomal abnormalities detected by multicolor fluorescence in situ hybridization in fine-needle aspirates from patients with small lymphocytic lymphoma are useful for predicting survival. Cancer. 2008; 114: 315-322.

95. Karhu R, Vilpo L, Isola J, Knuutila S, Vilpo J. Cryopreserved chronic lymphocytic leukemia cells analyzed by multicolor fluorescence in situ hybridization after optimized mitogen stimulation. Genes Chromosomes Cancer. 2002; 34: 345-348.

96. Mkrtchyan $\mathrm{H}$, Glaser $\mathrm{M}$, Gross $\mathrm{M}$, Wedding $\mathrm{U}$, Hoffken $\mathrm{K}$, Liehr $\mathrm{T}$, et al. Multicolor-FISH applied to resolve complex chromosomal changes in a case of T-ALL (FAB L2). Cytogenet Genome Res. 2006; 114: 270-273.

97. Karst C, Gross M, Haase D, Wedding U, Hoffken K, Liehr T, et al. Novel cryptic chromosomal rearrangements detected in acute lymphoblastic leukemia detected by application of new multicolor fluorescent in situ hybridization approaches. Int J Oncol. 2006; 28: 891-897.

98. Benkhaled L, Barrios L, Mestres M, Caballin MR, Ribas M, Barquinero JF. Analysis of gammarays induced chromosome aberrations: a fingerprint evaluation with a combination of pancentromeric and pan-telomeric probes. Int J Radiat Biol. 2006; 82: 869-875. 
99. Mestres M, Benkhaled L, Caballin MR, Barrios L, Ribas M, Barquinero JF. Induction of incomplete and complex chromosome aberrations by $30 \mathrm{kVp} X$ rays. Radiat Res. 2011; 175: 201-207.

100. Wu H, George K, Willingham V, Kawata T, Cucinotta FA. Comparison of F ratios generated from interphase and metaphase chromosome damage induced by high doses of low- and high-LET radiation. Radiat Res. 2001; 155: 57-62.

101. Berardinelli F, De Vitis M, Nieri D, Cherubini R, De Nadal V, Gerardi S, et al. mBAND and mFISH analysis of chromosomal aberrations and breakpoint distribution in chromosome 1 of AG01522 human fibroblasts that were exposed to radiation of different qualities. Mutat Res Genet Toxicol Environ Mutagen. 2015; 793: 55-63.

102. Greulich KM, Kreja L, Heinze B, Rhein AP, Weier HG, Bruckner M, et al. Rapid detection of radiation-induced chromosomal aberrations in lymphocytes and hematopoietic progenitor cells by mFISH. Mutat Res. 2000; 452: 73-81.

103. Loucas BD, Cornforth MN. Complex chromosome exchanges induced by gamma rays in human lymphocytes: an mFISH study. Radiat Res. 2001; 155: 660-671.

104. Darroudi F, Bezrookove V, Fomina J, Mesker WE, Wiegant JC, Raap AK, et al. Insights into the sites of $X$ ray and neutron induced chromosomal aberrations in human lymphocytes using COBRA-MFISH. Radiat Prot Dosimetry. 2002; 99: 189-192.

105. Raap AK, Tanke HJ. COmbined Binary RAtio fluorescence in situ hybridiziation (COBRA-FISH): development and applications. Cytogenet Genome Res. 2006; 114: 222-226.

106. Hande MP, Azizova TV, Burak LE, Khokhryakov VF, Geard CR, Brenner DJ. Complex chromosome aberrations persist in individuals many years after occupational exposure to densely ionizing radiation: an mFISH study. Genes Chromosomes Cancer. 2005; 44: 1-9.

107. Anderson RM, Marsden SJ, Paice SJ, Bristow AE, Kadhim MA, Griffin CS, et al. Transmissible and nontransmissible complex chromosome aberrations characterized by three-color and mFISH define a biomarker of exposure to high-LET alpha particles. Radiat Res. 2003; 159: 4048.

108. Wahab MA, Nickless EM, Najar-M'kacher R, Parmentier C, Podd JV, Rowland RE. Elevated chromosome translocation frequencies in New Zealand nuclear test veterans. Cytogenet Genome Res. 2008; 121: 79-87.

109. Livingston GK, Escalona M, Foster A, Balajee AS. Persistent in vivo cytogenetic effects of radioiodine therapy: a 21-year follow-up study using multicolor FISH. J Radiat Res. 2018; 59: 10-17.

110. Schmitz S, Pinkawa M, Eble MJ, Kriehuber R. Persisting ring chromosomes detected by mFISH in lymphocytes of a cancer patient-a case report. Mutat Res. 2013; 756: 158-164.

111. Pignalosa D, Bertucci A, Gialanella G, Grossi G, Manti L, Pugliese M, et al. Chromosome interand intrachanges detected by arm-specific DNA probes in the progeny of human lymphocytes exposed to energetic heavy ions. Radiat Res. 2008; 170: 458-466.

112. Boei JJ, Vermeulen S, Mullenders LH, Natarajan AT. Impact of radiation quality on the spectrum of induced chromosome exchange aberrations. Int J Radiat Biol. 2001; 77: 847-857.

113. Bauchinger $M$, Schmid $E$. LET dependence of yield ratios of radiation-induced intra- and interchromosomal aberrations in human lymphocytes. Int J Radiat Biol. 1998; 74: 17-25.

114. Hada M, Cucinotta FA, Gonda SR, Wu H. mBAND analysis of chromosomal aberrations in human epithelial cells exposed to low- and high-LET radiation. Radiat Res. 2007; 168: 98-105. 
115. Kodama Y, Ohtaki K, Awa AA, Nakano M, Itoh M, Nakamura N. The F value for chromosome aberrations in atomic bomb survivors does not provide evidence for a primary contribution of neutrons to the dose in Hiroshima. Radiat Res. 1999; 152: 558-562.

116. Wu H. Probabilities of radiation-induced inter- and intrachromosomal exchanges and their dependence on the DNA content of the chromosome. Radiat Res. 2001; 156: 603-606.

117. Asaithamby A, Chen DJ. Mechanism of cluster DNA damage repair in response to high-atomic number and energy particles radiation. Mutat Res. 2011; 711: 87-99.

118. Bielefeldt-Ohmann H, Genik PC, Fallgren CM, Ullrich RL, Weil MM. Animal studies of charged particle-induced carcinogenesis. Health Phys. 2012; 103: 568-576.

119. Curtis SB, Hazelton WD, Luebeck EG, Moolgavkar SH. From mechanisms to risk estimation-bridging the chasm. Adv Space Res. 2004; 34: 1404-1409.

120. Edwards AA. RBE of radiations in space and the implications for space travel. Phys Med. 2001; 17 Suppl 1: 147-152.

121. Harms-Ringdahl M, Nicotera P, Radford IR. Radiation induced apoptosis. Mutat Res. 1996; 366: 171-179.

122. Jostes RF. Genetic, cytogenetic, and carcinogenic effects of radon: a review. Mutat Res. 1996; 340: 125-139.

123. Limoli CL, Ponnaiya B, Corcoran JJ, Giedzinski E, Kaplan MI, Hartmann A, et al. Genomic instability induced by high and low LET ionizing radiation. Adv Space Res. 2000; 25: 2107-2117.

124. Moore S, Stanley FK, Goodarzi AA. The repair of environmentally relevant DNA double strand breaks caused by high linear energy transfer irradiation--no simple task. DNA Repair. 2014; 17: 64-73.

125. Yatagai F. Mutations induced by heavy charged particles. Biol Sci Space. 2004; 18: 224-234.

126. Camacho CV, Mukherjee B, McEllin B, Ding LH, Hu B, Habib AA, et al. Loss of p15/Ink4b accompanies tumorigenesis triggered by complex DNA double-strand breaks. Carcinogenesis. 2010; 31: 1889-1896.

127. Mitchell CR, Azizova TV, Hande MP, Burak LE, Tsakok JM, Khokhryakov VF, et al. Stable intrachromosomal biomarkers of past exposure to densely ionizing radiation in several chromosomes of exposed individuals. Radiat Res. 2004; 162: 257-263.

128. Johannes C, Horstmann M, Durante M, Chudoba I, Obe G. Chromosome intrachanges and interchanges detected by multicolor banding in lymphocytes: searching for clastogen signatures in the human genome. Radiat Res. 2004; 161: 540-548.

129. Tawn EJ, Whitehouse CA, Holdsworth D, De Ruyck K, Vandenbulcke K, Thierens H. mBAND analysis of chromosome aberrations in lymphocytes exposed in vitro to alpha-particles and gamma-rays. Int J Radiat Biol. 2008; 84: 447-453.

130. Cartwright IM, Genet MD, Fujimori A, Kato TA. Role of LET and chromatin structure on chromosomal inversion in CHO10B2 cells. Genome Integr. 2014; 5: 1.

131. Ray FA, Robinson E, McKenna M, Hada M, George K, Cucinotta F, et al. Directional genomic hybridization: inversions as a potential biodosimeter for retrospective radiation exposure. Radiat Environ Biophys. 2014; 53: 255-263.

132. Pignalosa D, Lee R, Hartel C, Sommer S, Nikoghosyan A, Debus J, et al. Chromosome inversions in lymphocytes of prostate cancer patients treated with $\mathrm{X}$-rays and carbon ions. Radiother Oncol. 2013; 109: 256-261. 
133. Hill MA. Fishing for radiation quality: chromosome aberrations and the role of radiation track structure. Radiat Prot Dosimetry. 2015; 166: 295-301.

134. Kline AD, Griffin CA, Haddadin MH, Chudoba I, Morsberger LA, Hawkins AL, et al. A de novo complex karyotype with two independent balanced translocations and a double inversion of chromosome 6 presenting with multiple congenital anomalies. Am J Med Genet A. 2004; 129A: 124-129.

135. Pignalosa D, Ritter S, Durante M. Inversions in chromosome 10 of human thyroid cells induced by accelerated heavy ions. Radiat Res. 2010; 174: 14-19.

136. Eastmond DA, Pinkel D. Detection of aneuploidy and aneuploidy-inducing agents in human lymphocytes using fluorescence in situ hybridization with chromosome-specific DNA probes. Mutat Res. 1990; 234: 303-318.

137. Pinkel D, Straume T, Gray JW. Cytogenetic analysis using quantitative, high-sensitivity, fluorescence hybridization. Proc Natl Acad Sci U S A. 1986; 83: 2934-2938.

138. Rupa DS, Hasegawa LS, Eastmond DA. Detection of chromosomal alterations affecting the 1cen-1q12 region in irradiated granulocytes and lymphocytes by multicolour FISH with tandem DNA probes. Mutagenesis. 1997; 12: 195-200.

139. Prasanna PG, Hamel CJ, Escalada ND, Duffy KL, Blakely WF. Biological dosimetry using human interphase peripheral blood lymphocytes. Mil Med. 2002; 167: 10-12.

140. Durante M, George K, Yang TC. Biological dosimetry by interphase chromosome painting. Radiat Res. 1996; 145: 53-60.

141. Jhiang SM. The RET proto-oncogene in human cancers. Oncogene. 2000; 19: 5590-5597.

142. Santoro M, Sabino N, Ishizaka Y, Ushijima T, Carlomagno F, Cerrato A, et al. Involvement of RET oncogene in human tumours: specificity of RET activation to thyroid tumours. Br J Cancer. 1993; 68: 460-464.

143. Burman B, Misteli T, Pegoraro G. Quantitative detection of rare interphase chromosome breaks and translocations by high-throughput imaging. Genome Biol. 2015; 16: 146.

144. Kozubek S, Lukasova E, Jirsova P, Koutna I, Kozubek M, Ganova A, et al. 3D Structure of the human genome: order in randomness. Chromosoma. 2002; 111: 321-331.

145. Hsu WL, Preston DL, Soda M, Sugiyama H, Funamoto S, Kodama K, et al. The incidence of leukemia, lymphoma and multiple myeloma among atomic bomb survivors: 1950-2001. Radiat Res. 2013; 179: 361-382.

146. Maifrede S, Martin K, Podszywalow-Bartnicka P, Sullivan-Reed K, Langer SK, Nejati R, et al. IGH/MYC Translocation Associates with BRCA2 Deficiency and Synthetic Lethality to PARP1 Inhibitors. Mol Cancer Res. 2017; 15: 967-972.

147. Atkin NB, Brito-Babapulle V. Heterochromatin polymorphism and human cancer. Cancer Genet Cytogenet. 1981; 3: 261-272.

148. Doneda L, Ginelli E, Agresti A, Larizza L. In situ hybridization analysis of interstitial Cheterochromatin in marker chromosomes of two human melanomas. Cancer Res. 1989; 49: 433-438.

149. Larizza L, Doneda L, Ginelli E, Fossati G. C-heterochromatin variation and transposition in tumor progression. Adv Exp Med Biol. 1988; 233: 309-318.

150. Larizza L, Doneda L, Rodolfo M, Fossati G. High incidence of chromosomal lesions involving Cheterochromatin in four human melanoma lines. Clin Exp Metastasis. 1989; 7: 633-644. 
151. Grosovsky AJ, Parks KK, Giver CR, Nelson SL. Clonal analysis of delayed karyotypic abnormalities and gene mutations in radiation-induced genetic instability. Mol Cell Biol. 1996; 16: 6252-6262.

152. Smith LE, Grosovsky AJ. Genetic instability on chromosome 16 in a human B lymphoblastoid cell line. Somat Cell Mol Genet. 1993; 19: 515-527.

153. Cho YH, Kim SY, Woo HD, Kim YJ, Ha SW, Chung HW. Delayed Numerical Chromosome Aberrations in Human Fibroblasts by Low Dose of Radiation. Int J Environ Res Public Health. 2015; 12: 15162-15172.

154. Brown N, Finnon R, Manning G, Bouffler S, Badie C. Influence of radiation quality on mouse chromosome 2 deletions in radiation-induced acute myeloid leukaemia. Mutat Res Genet Toxicol Environ Mutagen. 2015; 793: 48-54.

155. Solovei I, Cavallo A, Schermelleh L, Jaunin F, Scasselati C, Cmarko D, et al. Spatial preservation of nuclear chromatin architecture during three-dimensional fluorescence in situ hybridization (3D-FISH). Exp Cell Res. 2002; 276: 10-23.

156. Zink D, Cremer T, Saffrich R, Fischer R, Trendelenburg MF, Ansorge W, et al. Structure and dynamics of human interphase chromosome territories in vivo. Hum Genet. 1998; 102: 241251.

157. Cremer M, von Hase J, Volm T, Brero A, Kreth G, Walter J, et al. Non-random radial higherorder chromatin arrangements in nuclei of diploid human cells. Chromosome Res. 2001; 9: 541-567.

158. Kreth G, Finsterle J, von Hase J, Cremer M, Cremer C. Radial arrangement of chromosome territories in human cell nuclei: a computer model approach based on gene density indicates a probabilistic global positioning code. Biophys J. 2004; 86: 2803-2812.

159. Kupper K, Kolbl A, Biener D, Dittrich S, von Hase J, Thormeyer T, et al. Radial chromatin positioning is shaped by local gene density, not by gene expression. Chromosoma. 2007; 116: 285-306.

160. Sun HB, Shen J, Yokota H. Size-dependent positioning of human chromosomes in interphase nuclei. Biophys J. 2000; 79: 184-190.

161. Zeitz MJ, Mukherjee L, Bhattacharya S, Xu J, Berezney R. A probabilistic model for the arrangement of a subset of human chromosome territories in WI38 human fibroblasts. J Cell Physiol. 2009; 221: 120-129.

162. Boyle S, Gilchrist S, Bridger JM, Mahy NL, Ellis JA, Bickmore WA. The spatial organization of human chromosomes within the nuclei of normal and emerin-mutant cells. Hum Mol Genet. 2001; 10: 211-219.

163. Cremer T, Cremer C. Chromosome territories, nuclear architecture and gene regulation in mammalian cells. Nat Rev Genet. 2001; 2: 292-301.

164. Croft JA, Bridger JM, Boyle S, Perry P, Teague P, Bickmore WA. Differences in the localization and morphology of chromosomes in the human nucleus. J Cell biol. 1999; 145: 1119-1131.

165. loannou D, Kandukuri L, Simpson JL, Tempest HG. Chromosome territory repositioning induced by PHA-activation of lymphocytes: A 2D and 3D appraisal. Mol Cytogenet. 2015; 8: 47.

166. Lukasova E, Kozubek S, Kozubek M, Kroha V, Mareckova A, Skalnikova M, et al. Chromosomes participating in translocations typical of malignant hemoblastoses are also involved in exchange aberrations induced by fast neutrons. Radiat Res. 1999; 151: 375-384. 
167. Balajee AS, Sanders JT, Golloshi R, Shuryak I, McCord RP, Dainiak N. Investigation of Spatial Organization of Chromosome Territories in Chromosome Exchange Aberrations After lonizing Radiation Exposure. Health Phys. 2018; 115: 77-89.

168. Arsuaga J, Greulich-Bode KM, Vazquez M, Bruckner M, Hahnfeldt P, Brenner DJ, et al. Chromosome spatial clustering inferred from radiogenic aberrations. Int J Radiat Biol. 2004; 80: 507-515.

169. Foster HA, Estrada-Girona G, Themis M, Garimberti E, Hill MA, Bridger JM, et al. Relative proximity of chromosome territories influences chromosome exchange partners in radiationinduced chromosome rearrangements in primary human bronchial epithelial cells. Mutat Res. 2013; 756: 66-77.

170. Dekker J. The three ' $C$ ' s of chromosome conformation capture: controls, controls, controls. Nat Methods. 2006; 3: 17-21.

171. Dekker J, Marti-Renom MA, Mirny LA. Exploring the three-dimensional organization of genomes: interpreting chromatin interaction data. Nat Rev Genet. 2013; 14: 390-403.

172.Dekker J, Rippe K, Dekker M, Kleckner N. Capturing chromosome conformation. Science. 2002; 295: 1306-1311.

173. Lajoie BR, Dekker J, Kaplan N. The Hitchhiker's guide to Hi-C analysis: practical guidelines. Methods. 2015; 72: 65-75.

174. Murrell A, Heeson S, Reik W. Interaction between differentially methylated regions partitions the imprinted genes Igf2 and H19 into parent-specific chromatin loops. Nat Genet. 2004; 36: 889-893.

175. Spilianakis CG, Flavell RA. Long-range intrachromosomal interactions in the Thelper type 2 cytokine locus. Nat Immunol. 2004; 5: 1017-1027.

176. Tolhuis B, Palstra RJ, Splinter E, Grosveld F, de Laat W. Looping and interaction between hypersensitive sites in the active beta-globin locus. Mol Cell. 2002; 10: 1453-1465.

177. Lieberman-Aiden E, van Berkum NL, Williams L, Imakaev M, Ragoczy T, Telling A, et al. Comprehensive mapping of long-range interactions reveals folding principles of the human genome. Science. 2009; 326: 289-293.

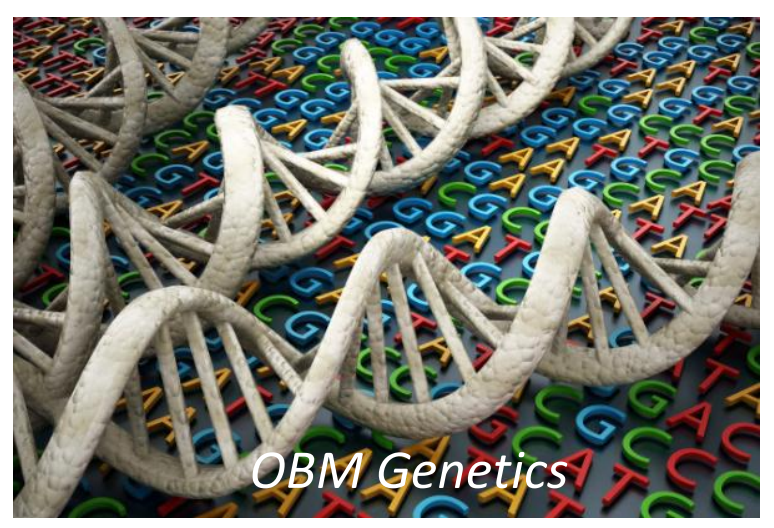

Enjoy OBM Genetics by:

1. Submitting a manuscript

2. Joining in volunteer reviewer bank

3. Joining Editorial Board

4. Guest editing a special issue

For more details, please visit:

http://www.lidsen.com/journals/genetics 